\title{
DYNAMICALLY INTEGRATING KNOWLEDGE IN TEAMS: TRANSFORMING RESOURCES INTO PERFORMANCE
}

\author{
HEIDI K. GARDNER \\ FRANCESCA GINO \\ Harvard University \\ BRADLEY R. STAATS \\ University of North Carolina at Chapel Hill
}

\begin{abstract}
In knowledge-based environments, teams must develop a systematic approach to integrating knowledge resources throughout the course of projects in order to perform effectively. Yet many teams fail to do so. Drawing on the resource-based view of the firm, we examine how teams can develop a knowledge-integration capability to dynamically integrate members' resources into higher performance. We distinguish among three sets of resources-relational, experiential, and structural-and propose that they differentially influence a team's knowledge integration capability. We test our theoretical framework using data on knowledge workers in professional services and discuss implications for research and practice.
\end{abstract}

Faced with a rapidly changing and competitive environment, many companies have turned to team-based approaches to build and maintain high performance and foster innovation (Gibson, Waller, Carpenter, \& Conte, 2007; Gino, Argote, MironSpektor, \& Todorova, 2010; Pearce \& Ensley, 2004). In a range of contexts, from consulting and product development to engineering and software services, work is delivered by fluid teams of knowledge workers who come together to execute a project before breaking up and moving on to the next project (Edmondson \& Nembhard, 2009; Huckman, Staats, \& Upton, 2009). Knowledge workers are individuals who process information rather than physical goods (Von Nordenflycht, 2010). In the context of an organization consisting of teams of knowledge workers, understanding firm performance involves examining team performance, since the organization's output is created through

Data in this article were collected as part of the first author's dissertation, and she thanks Christopher Earley, Randall Peterson, Madan Pillutla, and Phanish Puranam for guidance and London Business School for financial support. For helpful feedback on drafts, we are grateful to Richard Hackman and the Boston area GroupsGroup workshop, participants in Harvard Business School's OB Workshop and Micro-Topics in Organizational Behavior doctoral seminar, Michael Christian, Jeff Edwards, Virginia Kay, Jeffrey Polzer, and Ben Rosen. We also thank Associate Editor Raymond T. Sparrowe and three anonymous reviewers for their developmental and insightful comments throughout the review process. the execution of project teams (Haas \& Hansen, 2007; Huckman \& Staats, 2011).

These teams typically operate in dynamic contexts in which, to perform well, they must access and use each member's unique portfolio of resources. Although synergistic groups can outperform even extraordinary individuals (Laughlin, Bonner, \& Miner, 2002), as Hackman and Katz noted, the likelihood of a group's reaching its full potential "all depends on the degree to which the group has, and uses well, the full complement of resources that are required for exceptional performance" (2010: 10).

Several lines of work in the academic literature about teams address this question of what it means for a group to use its resources well, including research on transactive memory in groups (Austin, 2003; Lewis, 2004; Liang, Moreland, \& Argote, 1995), the pooling of members' distributed knowledge (Larson, Christensen, Abbot, \& Franz, 1996; Stasser, Stewart, \& Wittenbaum, 1995; Stewart \& Stasser, 1995), and the identification and sharing of members' functionally diverse or specialized knowledge (Bunderson, 2003; Bunderson \& Sutcliffe, 2002; Drach-Zahavy \& Somech, 2001). These different lines of research have provided important insights on how group members coordinate knowledge inputs and combine them into a collective outcome.

Yet the meaning of "using [resources] well" differs depending on a team's task (Carlile \& Rebentisch, 2003; Kozlowski, Gully, Nason, \& Smith, 1999; Steiner, 1972). In many team tasks, particularly those undertaken by knowledge workers who have discretion about how to conduct their prob- 
lem-solving discussions, using resources well is more than just a matter of identifying and then completing a transfer of members' disparate knowledge element (e.g., as in the case of a team assembling the clues in a hidden profile task). Rather, as Kozlowski and colleagues (1999) theorized, teams undertaking complex, rapidly changing work must integrate their members' knowledge in an ongoing process of mutual adjustment as their work is taking place to be successful (Thompson, 1967; Van De Ven, Delbecq, \& Koenig, 1976). It is therefore especially important for such teams to develop a systematic approach to integrating knowledge inputs that allows them to do so consistently throughout the course of a project; neither ad hoc problem solving nor unsystematic team communication is sufficient to provide the reliability required in this situation. As rich as the team literature is regarding the identification and transfer of members' knowledge, it is surprisingly silent about the way in which teams systematically integrate members' knowledge resources and do so dynamically in response to changing contextual features.

To delve into these questions, we draw on a literature from the field of strategy that traditionally has been used to understand how firms employ resources to generate superior performance: the resource-based view of the firm (Barney, 1991; Wernerfelt, 1984). Strategic management research has highlighted the importance for firms of developing internal capabilities and has demonstrated that internal firm capabilities are a key differentiator between firms that succeed and those that do not (Helfat \& Peteraf, 2003; Nelson \& Winter, 1982). Within the resource-based view literature, a stream of research focusing on firms' development of dynamic capabilities is particularly instructive for understanding processes used to integrate resources for enhanced performance. Specifically, dynamic capabilities are learned, repeatable patterns of actions that provide a systematic ability to integrate resources to enhance performance (Eisenhardt \& Martin, 2000; Teece, Pisano, \& Shuen, 1997; Zollo \& Winter, 2002). We bring the resource-based view and the construct of dynamic capabilities from the firm level to the team level. We propose that by doing so, we can begin to resolve an important theoretical puzzle in the team literature: Why do some teams fail to use their members' knowledge resources effectively? We argue that the answer lies in the failure of some teams to build a knowledge integration capability, which we define as a reliable pattern of team communication that generates joint contributions to the understanding of complex problems.
Therefore, this article examines how the development of a knowledge integration capability allows some teams to convert members' knowledge resources into higher performance, while others fail to develop this capability and leave resources untapped. Drawing from Kogut and Zander (1992), we distinguish among three sets of resources: relational (intrateam familiarity), experiential (collective work experience and training), and structural (how relational and experiential resources are distributed across team members). We develop theory to explain how these knowledge resources within a team are associated with the development of its knowledge integration capability, which is necessary for teams to reach-and sustain high levels of performance. We also explore how this development varies with task uncertainty. We present tests of our predictions using a combination of archival and longitudinal survey data collected in 79 audit and consulting teams from a global Big Four accounting firm.

Our theoretical model allows us to answer two important questions. The first relates to the understanding of why teams differ in their ability to convert member knowledge and expertise into performance. The second question examines the types of resources that facilitate the development of a knowledge integration capability and one condition (uncertainty) that may influence it. In answering these questions, we advance theory in both strategic management and team research. With respect to the former, we offer microlevel detail on the structuring and integration of knowledge-based resources. We identify one dynamic capability, a team's knowledge integration capability, and investigate what factors aid in its development and how it is associated with team performance. We also offer insight on how and where to deploy resources most effectively in teams and give guidance to management practice about the types of resource portfolios to build, finding that resources can be a double-edged sword: some knowledge resources improve performance, but others may diminish it.

With respect to research on teams, we build on a growing body of work that examines why some groups are more effective than others (Gardner, 2012; Hackman \& Katz, 2010; Ilgen, Hollenbeck, Johnson, \& Jundt, 2005) by exploring teams' capacity to develop dynamic capabilities for systematic, reliable knowledge integration. We examine how not only the amount of team resources but also their configuration relates to the development of team knowledge integration capability and ultimately team performance. Additionally, we examine an important moderating variable, task uncertainty, and explore how it corresponds to a team's ability to integrate knowledge. 
Thus, by integrating a teams and a strategy perspective, our study develops a theoretical framework within which future investigations of knowledgebased teamwork and team performance can be pursued more fruitfully and systematically.

\section{KNOWLEDGE UTILIZATION IN TEAMS}

The question of how teams use knowledge-based resources to achieve high levels of performance is not new in the literature. Indeed, three welldeveloped streams of research address how team members can leverage their knowledge stores to improve performance outcomes: work on transactive memory systems, information pooling, and functional diversity. According to the transactive memory approach, grounded in the work of Wegner and colleagues (Wegner, 1986; Wegner, Erber, \& Raymond, 1991), a shared knowledge system emerges in groups for learning, storing, and retrieving information. This system facilitates group performance by providing a guideline for matching member knowledge to group tasks, as demonstrated both in the lab (Lewis, Lange, \& Gillis, 2005; Liang et al., 1995; Littlepage, Robison, \& Reddington, 1997) and in organizational settings (Austin, 2003; Lewis, 2003). Research has shown that members' level of task knowledge and intrateam shared task experiences are antecedents to the development of transactive memory systems (Austin, 2003; Lewis, 2003) and that communication is a key factor in the development of a team's transactive memory (Lewis, 2004). Once a system is developed, group -members engage in three key communication practices to utilize it: directory updating (learning what others know), allocating information to deemed experts, and retrieving information from them (Hollingshead, 1998).

The information-pooling approach examines information exchange during team interactions; group discussions are framed as the means by which groups exchange unshared information (Stasser, Taylor, \& Hanna, 1989). Two central findings in this area have emerged: (1) teams favor information that is shared (commonly held) over information that is unshared (uniquely held), thereby harming performance (Stasser et al., 1989; Stasser \& Titus, 1985, 1987), and (2) team members' preferences are shaped more by more frequently discussed information (Stasser, Stella, Hanna, \& Colella, 1984). These dynamics are impacted by many factors, such as group size (Stasser et al., 1989), member familiarity (Gruenfeld, Mannix, Williams, \& Neale, 1996), and affectivity (Kooij-de Bode, van Knippenberg, \& van Ginkel, 2010).
Work on functional diversity examines the distribution of team members across a variety of functional categories and how these differences facilitate or hinder team interactions as teams pursue their objectives (Bunderson \& Sutcliffe, 2002; Drach-Zahavy \& Somech, 2001). Empirical work in this area related to the use of team knowledge focuses on team members' efforts to share information and keep each other current on key issues (Bunderson \& Sutcliffe, 2002; Cummings, 2004; Huckman \& Staats, 2011). Individual members who have a broad functional background tend to be motivated to share knowledge because they understand its value to the whole task and believe teammates will accept it; in contrast, if each team member is a deep specialist whose knowledge does not overlap with that of others, knowledge sharing is more likely to suffer (Cronin \& Weingart, 2007).

These three streams of research on the link between leveraging teams' knowledge resources and team performance support three clear conclusions: (1) group performance and decision quality improve when members possess the right type and level of task knowledge, (2) outcomes are better when team members are aware of the knowledge others hold, and (3) the distribution of knowledge resources within teams affects their ability to share and pool information from different members. Together, these findings parallel the view in the dynamic capabilities literature, detailed below, that experiential, relational, and structural knowledge resources are critical for performance.

Yet these findings also highlight two implications that warrant further examination. First, even after overcoming the difficulties of sharing knowledge, teams vary in their abilities to use member knowledge to solve problems or make better decisions (Hackman \& Katz, 2010). Although a great deal is known about whether information will be shared (Bunderson \& Sutcliffe, 2002; Drach-Zahavy \& Somech, 2001) and to some degree whether it will be accessed and pooled into a joint outcome (Stasser et al., 1989; Stasser \& Titus, 1985, 1987), far less is known about teams' ability to integrate and transform knowledge into novel solutions to address complex problems.

Second, for teams facing a project that extends over a long time, the process of integrating members' knowledge is more than just a matter of identifying and then completing a one-time transfer. Instead, it requires team members to engage in ongoing mutual readjustments (Kozlowski et al., 1999; Zollo \& Winter, 2002). Especially when operating in dynamic and uncertain environments, teams must develop a systematic approach for consistently integrating members' knowledge through- 
out their projects' duration; ad hoc problem solving is inadequate to provide the necessary reliability. Important questions arise from these implications: Why are some teams better than others at converting member knowledge and expertise into performance, especially on lengthy, complex tasks? What types of resources facilitate knowledge integration, and under what conditions will teams be more or less effective at knowledge integration?

These questions become especially critical as researchers move their studies from ad hoc groups facing discrete, short-term tasks in lab settings to intact groups in today's organizations, in which teams must continually adapt and readapt to a barrage of shifting demands. Each of the team literature streams reviewed above offers an important piece of an explanation of how teams' members work together to solve complex problems. Yet prior work has not provided a conceptualization and measure of a team-based capability that captures a team's ability to reliably integrate its knowledge resources over time - a capability that allows teams to reach high levels of performance. Nor has it developed a framework for theorizing how contextual demands such as task uncertainty affect this capability. We address both theoretical gaps by drawing on the strategy literature on dynamic capabilities and the resource-based view of the firm.

\section{THEORETHICAL MODEL AND HYPOTHESES}

The resource-based view of the firm explores how firms develop reliable ways to integrate knowledge resources to generate superior performance, even when facing uncertain contexts. It suggests that organizations are made up of unique combinations of heterogeneous resources (Wernerfelt, 1984) used to construct or alter capabilities to create value (Barney, 1991; Nelson \& Winter, 1982; Sirmon, Hitt, \& Ireland, 2007). It is not merely possessing resources but the ability to deploy them productively that transforms firms' resources into valuable capabilities (Teece et al., 1997). Although resource-based view and capability building are both traditionally conceptualized as organizationlevel phenomena, at the core of each are individuals, nested in groups (e.g., teams or departments), who are responsible for executing activities (Argote \& Ingram, 2000; Helfat \& Peteraf, 2003). We therefore suggest that the concepts of the resource-based view extend to the team level: just as an organization needs to strategically leverage its resources, a team must use members' experiences and expertise to deliver project outcomes.

Our investigation focuses on knowledge resources because knowledge is the most critical competitive asset that a firm can possess (Grant, 1996). Drawing on Kogut and Zander's (1992) work firm knowledge, we examine three classes of team knowledge resources: relational, experiential, and structural. A team's relational resource captures individuals' prior shared work experience, or knowledge acquired by working together on the same team (Espinosa, Slaughter, Kraut, \& Herbsleb, 2007; Huckman et al., 2009). A team's experiential resource measures team members' know-how, defined as "the accumulated practical skill or expertise that allows one to do something smoothly and efficiently" (von Hippel, 1988: 6). For instance, individuals' industry and firm experience and their work-related training contribute to a team's experiential resource. Finally, not only does the level of a resource matter, but so too does its structure within the team (Dierickx \& Cool, 1989; Kogut \& Zander, 1992; Teece et al., 1997). Here, we consider the distribution of relational and experiential resources across the team (the extent to which each resource is concentrated in a small number of members or distributed more evenly among team members).

Although assembling resources is a necessary first step in generating team performance, resources must then be converted into a valuable capability-a process known in the resource-based view of the firm literature as bundling or integration (Sirmon et al., 2007; Sirmon, Gove, \& Hitt, 2008; Sirmon \& Hitt, 2009). Integrating resources is inherently a challenge in coordination (Adner \& Helfat, 2003; Helfat \& Peteraf, 2003), which is not a static exercise. Rather, successful performance depends on continuous integration as circumstances change-a knowledge integration capability (Eisenhardt \& Martin, 2000; Teece et al., 1997; Zollo \& Winter, 2002).

We use the term "dynamic knowledge integration capability" to refer to a reliable pattern of team communication that generates joint contributions to the understanding of complex problems in a team. Having communications at the heart of our construct is consistent with prior resource-based view literature, which contains theory and research asserting that communication is an essential, generalizable feature of most dynamic capabilities (Eisenhardt \& Martin, 2000). Translating the definition from the resource-based view of the firm to the group level implies that a team dynamic knowledge integration capability involves three interrelated aspects. First, existing research suggests that team communications reliably produce better results to the extent that they are efficient and do not overwhelm, confuse, or distract their receivers (Cronin \& Weingart, 2007). Therefore, communications between team members need to be concise, timely, and in the right amount (Apker, Propp, 
Zabava Ford, \& Hofmeister, 2006). Second, studies examining factors that enable teams to capture the best ideas and inputs across members-that is, to produce truly joint contributions-suggest that team interactions need to support members' participation and foster teamwork (Edmondson, 1999) rather than encouraging political or motivated knowledge sharing (Wittenbaum, Hollingshead, \& Botero, 2004). Such collaborative interactions promote rich, unemotional debate instead of confrontations that can undermine members' willingness to express doubts or accept others' opinions (Kozlowski et al., 1999). Third, recombining existing knowledge to solve complex problems requires teams to communicate content that is relevant, objective, and clear so that members can see the validity of their own and others' contributions, allowing them to discuss, evaluate, and apply ideas (Bunderson \& Sutcliffe, 2002; Hoegl \& Gemuenden, 2001).

In short, the dynamic capabilities literature provides a foundational definition for team knowledge integration capability, and small group research suggests that the characteristics of efficiency, collaborativeness, and validity are all essential components of that capability. Thus, although strategy research falls short in giving scholars clear guidance on how best to measure a firm-level capability, small groups research provides insight on the dimensions most critical for developing a measure of team knowledge integration capability.

\section{Team Knowledge Resources and Team Knowledge Integration Capability}

The extent to which team members have worked with one another in the past and are thus familiar with one another (i.e., relational resources) has been shown to improve general team performance (Espinosa et al., 2007; Goodman \& Leyden, 1991; Reagans, Argote, \& Brooks, 2005; Staats, Valentine, \& Edmondson, 2011). We propose that enhancing the knowledge integration capability within a team corresponds to better performance. Relational resources can help team members improve the validity, efficiency, and collaborativeness of their ongoing communication, thereby enhancing knowledge integration.

First, higher levels of team relational resources enhance the perceived validity of intrateam communication by shaping the cognitive structures of team members. More familiar group members engage in greater "perspective-taking" (Krauss \& Fussell, 1990), developing a more accurate and complete understanding of what their teammates need to move forward on a task. This process is enhanced when an individual possesses an awareness of what her/his team members do and do not know (Moreland \& Myaskovsky, 2000). In such a case, team members familiar with one another are likely to deliver content well tailored to their audience, who will perceive the communication as more valid, relevant, and clear than they would do otherwise.

Greater relational resources also can improve the efficiency with which members integrate knowledge. Group members who work together are more likely to develop a shared vocabulary (Cramton, 2001; Monteverde, 1995) that enables them to understand one another and exchange information efficiently. A shared vocabulary and other sources of common ground or mutual knowledge that arise from shared experience (Krauss \& Fussell, 1990) increase the likelihood that knowledge integration will be effective (Clark \& Marshall, 1981). By working with each other over time, group members learn who has what expertise (e.g., Hollingshead, 1998; Lewis, 2004) and how much information they need to retrieve and provide in a given situation. These repeated experiences are valuable for the ongoing sharing and adaptation that knowledge integration requires (Hansen, 1999).

Finally, greater relational resources improve the collaborativeness of group communications, enabling more widespread participation and joint problem solving. As group members increasingly interact, they develop shared beliefs that directly influence trust (Gruenfeld et al., 1996). In fact, team members are more likely to trust knowledge shared by known team members than that offered by unknown ones (Gruenfeld, Martorana, \& Fan, 2000; Kane, Argote, \& Levine, 2005). Once trust is in place, group members are more willing to take risks (Edmondson, 1999), and knowledge integration improves as ideas are shared more freely and openly (Dirks, 1999; Zand, 1972). Thus, we hypothesize the following:

Hypothesis 1. A team's relational resources are positively associated with the team's knowledge integration capability.

In addition to relational resources built through team members' previous work with one another, a second important knowledge resource that teams can access is their members' accumulated work expertise, or know-how. As Kogut and Zander (1992) noted, such knowledge is not strategically valuable by itself, but rather gains value when combined through capabilities that permit the creation of new knowledge. Team experiential resources are linked to both firm (e.g., Dimov \& Shepherd, 2005; Zarutskie, 2010) and team performance (Gardner, 2012). These resources are especially critical in the context of knowledge-intensive organizations such 
as professional service firms, where most of the firms' knowledge resources reside in their employees (Hitt, Bierman, Uhlenbruck, \& Shimizu, 2006; Von Nordenflycht, 2010).

Greater experiential resources should aid knowledge integration for several reasons. First, greater work experience is likely to increase a team member's knowledge of relevant topics, thereby improving the relevance, clarity, and accuracy of the individual's knowledge (Schmidt, Hunter, \& Outerbridge, 1986), as well as the efficiency with which it can be exchanged. Team members may also be able to draw on past models of knowledge integration from their own previous projects in creative ways that benefit the overall information processing of their current group (Littlepage et al., 1997; Reagans et al., 2005). With greater prior work experience, team members should also be more confident about the validity of their own and others' contributions, motivating them to share knowledge freely (Bunderson \& Sutcliffe, 2002).

Further, the more work experiences team members have, the more likely it is that at least some of those experiences will resemble those of other team members, enabling them to develop a compatible set of expectations about projects, clients, situations, and so forth (Cronin \& Weingart, 2007). In other words, even if team members have not worked directly with one another, greater separate work experience on similar projects will allow members to generate a compatible knowledge base, improving collaborativeness and thus aiding their knowledge integration capability (Bunderson \& Sutcliffe, 2003). Thus, we predict:

\section{Hypothesis 2. A team's experiential resources are positively associated with the team's knowledge integration capability.}

Although the levels of both relational and experiential resources within a team affect development of the knowledge integration capability, so too does the structure of resources (Dierickx \& Cool, 1989; Kogut \& Zander, 1992; Sparrowe, Liden, Wayne, \& Kraimer, 2001; Staats et al., 2011; Teece et al., 1997). In other words, we suggest that how a team's relational and experiential resources are distributed across team members can have important implications for the team.

We first examine the consequences of the distribution of relational resources across team members. Relational resources enable members to successfully locate knowledge within a group, share their knowledge, and respond to others' knowledge (Edmondson, 1999; Gruenfeld et al., 1996; Lewis et al., 2005). Therefore, when relational resources are distributed more broadly across dyads, holding the aggregate level of relational resources constant, these collaborative benefits are more likely. In contrast, when relational resources are concentrated within a small number of team members, the broader group is likely to have difficulty efficiently and effectively integrating its knowledge because of unshared beliefs and information. This idea is consistent with research on "fault lines" in teams that shows that the presence of concentrated subgroups can hamper team processes (Lau \& Murnighan, $1998,2005)$. Concentrated relational resources in a team may also lead to inefficient help seeking, since familiar members may be comfortable talking only to small subsets of team members whom they know and trust but not to other members whose knowledge may be equally important to the task at hand (Hofmann, Lei, \& Grant, 2009).

Research on social networks also supports the view that distributed relational resources may be especially valuable for a team (Reagans \& Zuckerman, 2001). If relational resources are widely distributed across an intrateam network, then network density or social closure may improve both trust and information exchange (Coleman, 1988; Portes \& Sensenbrenner, 1993). Thus, we propose the following hypothesis:

Hypothesis 3a. Distributed relational resources within a team are positively associated with the team's knowledge integration capability.

Next, we turn to the distribution of experiential resources within a team. The question is whether teams benefit more from having their work experience concentrated in a small number of members, or if widely distributed experience (holding constant the amount of experience) is more beneficial for maximizing knowledge integration.

Broader distribution of experiential resources is likely to undermine the efficiency of team communication, thereby impeding the development of a knowledge integration capability. Teams need clear direction to coordinate the integration of members' knowledge inputs (Hackman, 2002). People are most likely to take direction from those they perceive as having legitimate task knowledge (Lewis, 2004), and work experience is an important source of legitimacy in most task settings. It follows that having experiential resources more concentrated within a few team members will provide a team with a more streamlined set of directions and thereby enhance the efficiency of their communications.

In addition, wide resource distribution generally diminishes both the collaborativeness and validity (i.e., perceived relevance and objectivity) of team communications. At the extreme, completely dis- 
tributed experiential resources in a team imply that all members have the same level of work experience. Without clear differences in their levels of experience, team members may engage in direct rivalries for dominance over the group's process and output, reducing information exchange and collaboration (Bendersky \& Hays, 2012; Hambrick, 1994). Further, group members' level of work experience is likely to intertwine with their egos and identity (Polzer, Milton, \& Swann, 2002), in such a way that task debates may escalate into unproductive conflicts in which participants' egos are at stake (Jehn \& Mannix, 2001), leading people to strategically manipulate their knowledge sharing and use (Wittenbaum et al., 2004). The more team members vie for influence or dominance in a team, the less likely others will be to believe that their communication is unbiased and objective. Thus, the more evenly experiential resources are distributed across a team, the more likely that competitive dynamics will undermine collaboration and the validity of team communication, and disrupt team knowledge integration capability. We therefore predict the following:

Hypothesis 3b. Distributed experiential resources within a team are negatively associated with the team's knowledge integration capability.

\section{The Moderating Effect of Uncertainty on the Link between Resources and Knowledge Integration Capability}

Teams increasingly work in turbulent, unpredictable environments (Kozlowski et al., 1999). Both external environment and internal team context can create uncertainty about a team's task, including the nature of individuals' work, the steps and knowledge required to complete their task, and even the demands of clients when expectations are shifting rapidly. Following prior research, we define task uncertainty as members' having incomplete information about the task they are facing (Argote, Turner, \& Fichman, 1989; Galbraith, 1973). To integrate knowledge when teams are facing an uncertain task, it is essential for them to communicate openly and exchange information clearly and truthfully. In fact, when a team encounters uncertain tasks, even the steps needed to reach an outcome may not be clear; thus, team members must exchange adequate and appropriate information to minimize wasted time, openly reveal their preferences to avoid conflict over work assignments, and concisely convey their plan of action and check in with other team members to avoid duplication.
We posit that relational resources will have a stronger positive association with teams' knowledge integration capability under more uncertain task conditions. Teams that have prior experience working together have developed more accurate expectations about each other's knowledge (Mathieu, Goodwin, Heffner, Salas, \& Cannon-Bowers, 2000; Rentsch \& Hall, 1994). We expect that this certainty about team members makes teams less anxious when facing uncertainty about a task. Task uncertainty is a source of arousal; people feel tense and stressed when uncertain about a task and respond in ways consistent with "threat-rigidity" predictions (Argote et al., 1989), including reduced cognitive functioning and constricted control (Staw, Sandelands, \& Dutton, 1981). These threats impede knowledge integration by reducing information sharing, reducing discussion of shared information, and concentrating influence over decision making (Argote et al., 1989; Gladstein \& Reilly, 1985). Even if teams do experience arousal resulting from task uncertainty, relational resources may counter these tendencies that would otherwise disrupt knowledge integration. Prior research has shown that more familiar groups display disinhibition, or gradual nonconformity to behavioral norms and expectations (Orengo Castellá, Zornoza Abad, Prieto Alonso, \& Peiró Silla, 2000), and that strong interpersonal relations make members more willing to behave in ways inconsistent with a traditional status hierarchy (Leik, 1963). In teams with greater relational resources, therefore, members may feel more comfortable resisting the constriction of control that naturally happens under uncertainty. Thus, we expect teams in organizational settings to be able to draw on their relational resources to integrate their knowledge more effectively in the face of uncertainty:

Hypothesis 4. Uncertainty moderates the relationship between a team's relational resources and knowledge integration capability: The positive effect of relational resources is stronger under high uncertainty than under low uncertainty.

Although we hypothesize that relational resources help teams integrate their knowledge in the face of uncertainty, a dynamic capabilities perspective leads us to a different prediction for experiential resources. Namely, extant work shows that when organizations encounter changing and dynamic circumstances, prior experience may become a "core rigidity" or a "competency trap" (Leonard-Barton, 1992; Levitt \& March, 1988). Uncertain circumstances require exploration to identify an appropriate and perhaps even new ap- 
proach, yet experienced organizations may wrongly attempt to exploit only their existing knowledge (March, 1991; Teece et al., 1997).

Extending this line of thinking to the team level suggests that the level of experience may hurt, more than help, knowledge integration when teams face uncertain conditions. First, teams with higher levels of experience may be more set in their ways. Even though these teams have greater experience, when they face uncertain conditions they may be less likely to engage in knowledge integration instead of sticking to their existing routinized approach (Gersick \& Hackman, 1990). Additionally, more experienced team members may escalate their commitment to their existing solutions, so that even if others attempt to engage in knowledge integration, the overall climate for such behavior is poor. ${ }^{1}$

Under this logic, we reason the following:

Hypothesis 5. Uncertainty moderates the relationship between a team's experiential resources and its knowledge integration capability: The effects of experiential resources are less positive under high uncertainty than under low uncertainty.

We also expect uncertainty to moderate the relationship between the distribution of relational resources in a team and the team's knowledge integration capability. In particular, uncertainty is likely to correspond to an increase in the benefits of broadly distributed relational resources across a team. When facing uncertain tasks, team members need to rapidly and repeatedly draw on the knowledge of other team members, and distributed relational resources will enable efficient and effective integration across more linkages in the team. If only a subset of team members have worked with others in the past, it will be more difficult for all team members to communicate with one another when they particularly need to do so, and it will be harder to combat the anxiety and stress that task

\footnotetext{
${ }^{1}$ An additional question is whether higher levels of experience represent increased diversity in underlying knowledge. Consistently with a dynamic capabilities perspective, with levels of experience we make the assumption that the type of experience is generally similar. Diversity in experience type could harm knowledge integration, owing to process conflicts Uehn, Northcraft, \& Neale, 1999), or aid knowledge integration, owing to alternative perspective-taking, which helps organization members break out of competency traps (e.g., Pelled, Eisenhardt, \& Xin, 1999). Though a valuable topic for future research, diversity in experience type is outside the bounds of our empirical examination.
}

uncertainty tends to produce (Argote et al., 1989). When faced with uncertainty, teams need to seek help efficiently from others. But without widely distributed relational resources that aid in trust building and information sharing (Coleman, 1988; Portes \& Sensenbrenner, 1993), discussions to integrate knowledge may not occur, or those discussions that do occur may be less effective because of unclear content, poor timing, or confrontation. Thus, we hypothesize:

Hypothesis 6a. Uncertainty moderates the re-
lationship between a team's distribution of re-
lational resources and its knowledge integra-
tion capability: The positive effect of
distributed relational resources is stronger un-
der high uncertainty than under low
uncertainty.

We also expect uncertainty to moderate the relationship between the distribution of experiential resources in a team and the team's knowledge irtegration capability. As posited above, distributed experiential resources undermine the efficiency of team communication by spreading responsibility for task direction, resulting in confusion abocit whose knowledge should hold most sway in the collective task and diminishing the team's knowiedge integration capability. Further, greater resource distribution inhibits the collaborativeness and validity of team communications. When a tearn is uncertain about its task, these negative effects on knowledge integration are likely to be even worse, because uncertainty demands efficient and ongoing information exchange (Galbraith, 1973). Thus, we hypothesize the following:

Hypothesis 6b. Uncertainty moderates the relationship between a team's distribution of experiential resources and its knowledge integration capability: The negative association of distributed experience is stronger under high uncertainty than under low uncertainty.

\section{Team Knowledge Integration Capability and Performance}

Ongoing knowledge integration in teams can aid their performance (Eisenhardt \& Martin, 2000; Teece et al., 1997; Zollo \& Winter, 2002). Effectiv knowledge integration improves team efficier$c y$-it ensures that the right information is moving back and forth between the right team members at the right time so that they can solve the ongoing problems they encounter (Argote, 1999; Argote \& Ingram, 2000). With a knowledge integration capability, team members work collaboratively in a way 
that encourages ongoing, constructive dialogue so that the valuable resources in the team can be effectively utilized for team performance. Finally, when teams' integrate knowledge effectively, they communicate information that is relevant, objective, and clear, allowing team members to identify the validity of their own and others' contributions. This permits members to use one another's ideas to aid team performance (Bunderson \& Sutcliffe, 2002; Hoegl \& Gemuenden, 2001). Thus, we hypothesize the following:

Hypothesis 7. A team's knowledge integration capability is positively associated with the team's performance.

\section{Moderated Mediation Model}

Figure 1 depicts our full theoretical model. Hypotheses 1,2, and 3 predict that relational, experiential, and structural resources are related to a team's knowledge integration capability. Hypotheses 4,5 , and 6 predict that task uncertainty moderates the relationship between the resources the team possesses and its knowledge integration capability. Hypothesis 7 predicts a positive relationship between knowledge integration capability and performance. Together, these seven hypotheses specify a moderated mediation model (Edwards \& Lambert, 2007) in which interaction between uncertainty and the three resources indirectly influences team performance by contributing to the knowledge integration capability. Thus, we offer our final summary hypothesis:

Hypothesis 8. A team's knowledge integration capability mediates the moderating effects of uncertainty in the relationship between the team's relational, experiential, and structural resources and the team's performance.

\section{METHODS}

The professional services sector is a rich setting that offers several benefits for our investigation into the relationship of resources, uncertainty, and knowledge integration with team performance. Managing knowledge work and workers is a primary competitive challenge in the 21st century (Haas \& Hansen, 2007). Because knowledge is both the key input and key output in professional services firms, these firms are viewed as an archetype of knowledge-intensive firms (Alvesson, 1993; Starbuck, 1992). And because the project team is the primary vehicle for conducting work in these firms (Werr \& Stjernberg, 2003), it is important to examine these phenomena at the team level.

Further, researching project teams in professional services firms offers practical benefits. For example, projects' duration (from team origination to project completion) is often limited to several months, thus offering a chance to follow teams through their entire lifecycle. These firms provide a rich, field-based context in which to examine the

FIGURE 1

Theoretical Model

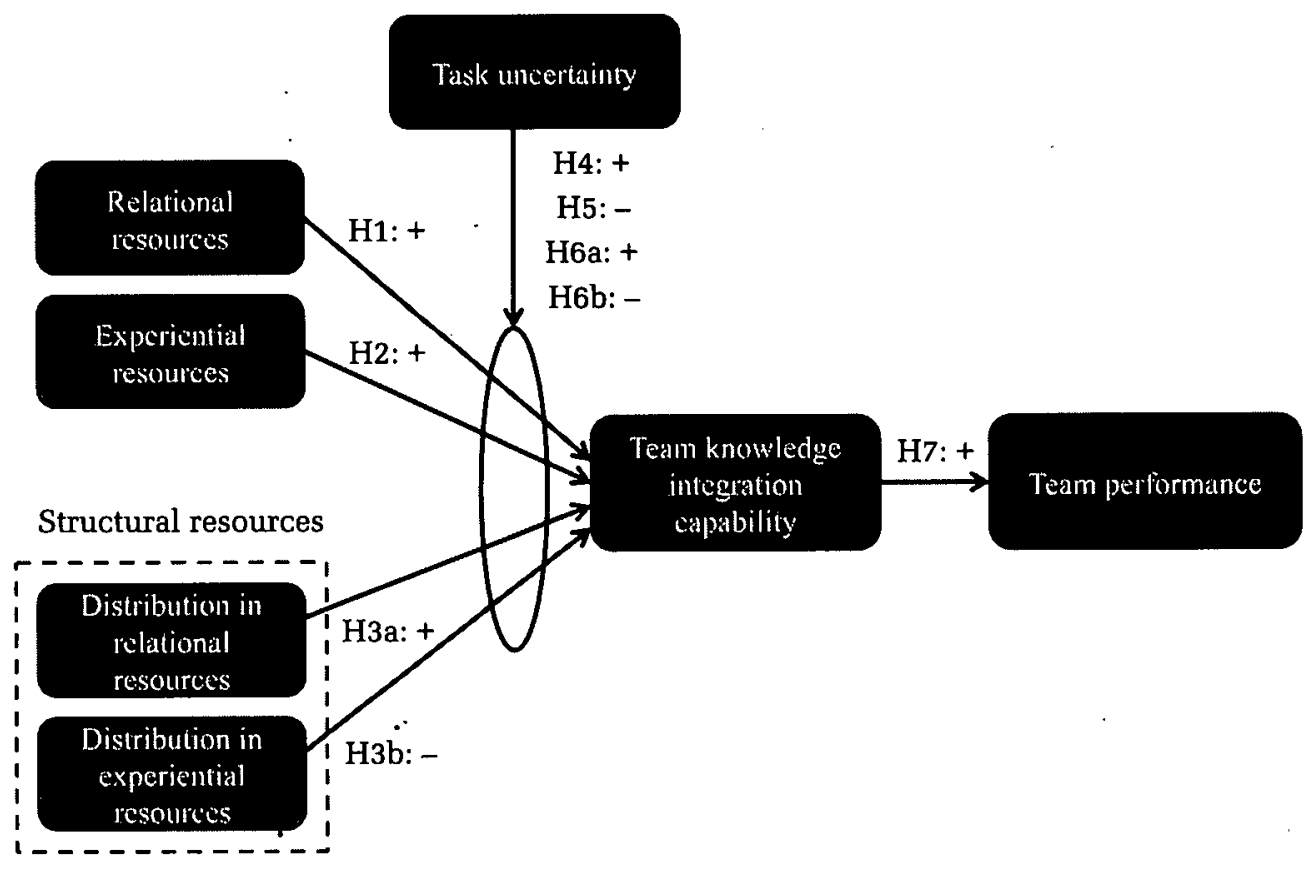


association of uncertainty with a team's ability to leverage its internal resources to produce successful performance outcomes.

\section{Design Overview}

Our overarching research design was intended to minimize issues of same-source bias to the greatest extent possible. To this end, we collected team process data from team members and contextual and performance data from partners who were responsible for the projects but uninvolved in day-today project work. We also collected data for constructing the independent and control variables from archived information.

\section{Sample}

We drew on a sample from the two largest divisions, audit and consulting, of a global, Big Four accounting firm that we will call "AuditCo." Our aim was to capture a sample that realistically would represent the range of tasks that AuditCo teams confront. The chief operating officer of AuditCo, our primary research contact for the project, and his office accordingly compiled an initial list of active project teams. We contacted teams from this list if they met certain logistical criteria (i.e., a project start date within 8 weeks, project duration of 3-16 weeks, and 3-10 full-time team members). Once we gained consent from the lead partner for each client team, we surveyed 722 individuals on 104 teams.

Individuals were considered to be part of a core team for a project only if they were employees of AuditCo and spent at least 50 percent of their time on the project. This definition therefore excludes (1) most firm partners (whose typical daily workload includes at least two "live" projects as well as other responsibilities); (2) internal firm experts (e.g., practice specialists); (3) other firm support personnel (e.g., library researchers, secretaries); and (4) client employees who provided assistance to the team.

\section{Measures}

Two surveys were sent to each team member. Survey 1 included the relational resource and uncertainty variables and was sent within a team's first three days on its project. Survey 2, administered during the team's final week on the project, asked team members to rate the team's knowledge integration capability. In general, people responded within four days of receiving the survey. Five hundred people answered both surveys. The response rate for survey 1 was 82 percent, and it was 70 percent for survey 2 . Sixty-six percent of the respondents were male; their average age was 30 years, and their average number of years working at AuditCo was 4.7. These figures closely mirror the demographic profile of the overall firm, according to statistics provided by AuditCo's human resources department.

For each participating team, we surveyed a senior partner who was responsible for the relationship with the client with which the team's project was connected and ultimately for assessing the team's performance but who had not been involved in day-to-day work of the team. This survey provided input on team performance and some control variables and was collected within one month of each project's completion.

Analyses provided evidence that it was appropriate to aggregate the team-rated items (knowledge integration capability, uncertainty, communication volume, and project demands) to the team level (Klein \& Kozlowski, 2000): in interrater agreement results $r_{\mathrm{wg}(\boldsymbol{)})}$ statistics exceed .80 for all variables, and interrater reliability results showed positive ICC1 results with significant $F$-values ( $p<.05$ ). For uncertainty, relational resources, and experiential resources, we centered all variables prior to entering them in the models to facilitate interpretation and minimize multicollinearity with the interaction terms (Aiken \& West, 1991).

Knowledge integration capability. Survey 2 asked team members to describe the exchanges of knowledge within their team using a seven-point scale that ranged from positive through neutral to negative. For example, the first item that respondents rated was "Communications within our team were . . . Relevant-Neutral-Irrelevant." The survey items measure different dimensions of effective and efficient information sharing and high-quality intrateam communications that capture a team's knowledge integration capability (Hoegl \& Gemuenden, 2001; Leathers, 1972): relevance, timeliness, objectivity, clarity, supportiveness, conciseness, truthfulness, nonconfrontational, adequacy, and fostering teamwork. Appendix A provides the exact wording of items used to assess each team's knowledge integration capability. Factor analysis confirmed that all items loaded onto a single factor; therefore, we averaged responses to create a single score per team $\left(\alpha=.95\right.$; mean $\left.r_{\mathrm{wg}(j)}=.93\right)$.

Team performance. The extent to which a team's output meets or exceeds its key stakeholders' standards is a core indicator of team effectiveness (Hackman \& Walton, 1986). We used assessments from each project team's responsible partner as the basis for evaluating team performance. Using 
five-point agreement scales, each partner scored his/her team on four survey items: "The client was $100 \%$ satisfied with the outcome of this audit," "Based on their satisfaction with this year's audit, the client is very likely to recommend AuditCo to other companies," "The AuditCo team communicated effectively (i.e., in a timely, clear, concise, non-confrontational way) with the client throughout the audit [project] cycle," and "This team was excellent in communicating the value of the audit [project] to the client." Item scores were averaged to create a single score of team performance each team $(\alpha=.76)$.

Task uncertainty. Survey 1 directed team members thus: "Please answer the following questions based on your individual assessment of the task." Following Van de Ven and Delbecq (1974), we used three items to measure task uncertainty, each of which was reverse-coded: "There is a clearly defined body of knowledge or subject matter that I can use to guide my work on this particular client project," "I understand the sequence of steps that I can follow to complete this project," and "It is clear to me what the outcome of this project will look like." Responses were averaged to create a single score of task uncertainty per team $\left(\alpha=.75\right.$; mean $r_{\mathrm{wg}(j)}$ was .88.

Relational resources. To measure relational resources, prior work has relied on experimental methods (e.g., Littlepage et al., 1997) or archival data (e.g., Reagans et al., 2005). Given that the firm's archival data did not track relational resources, we constructed a survey to measure individuals' prior shared work experience. On survey 1 , all team members were given a roster of their teammates and asked to indicate how many months they had previously worked with each other member, using a five-point scale $(1=$ "no prior experience together"; $2=$ " $<2$ months"; $3=$ "26 months"; $4=$ "6-12 months"; $5=$ "more than one year"). To create a team-level measure of relational resources, we averaged the responses across each reported dyadic relationship.

Experiential resources. To capture the experiential resources of each team, we used three indicators of team members' prior experience: organizational tenure, professional tenure (i.e., number of years in accounting for auditors, or in consulting for consultants), and level of professional/technical qualifications (i.e., level of technical certification/degree), in keeping with prior research (e.g., Hitt et al., 2006).

In using this approach we capture the quantitative aspects of team members' prior experience (Quinones, Ford, \& Teachout, 1995; Tesluk \& Jacobs, 1998); to capture multiple levels of specificity (e.g., organizational and job), we used both organi- zational and professional tenure as a measure of an individual's experience with the organization and in his/her specific job. This is a reasonable proxy in our setting as work is completed through projects that are, on average, of similar lengths. Because our teams consist of auditors or consultants who are not multifunctional, we assume that individuals' projects are of a similar type.

The three items were standardized separately by division and then averaged to create a composite score for each person. Team members completed these items as part of a larger set of demographic questions at the end of survey 1 . Team members' scores were averaged to create a team-level measure of experiential resources.

Distribution of relational resources. To measure within-team distribution of relational resources, we used the Blau index (Blau, 1977). This measure captures how prior experience working together between any two members in the team is spread across team members (Harrison \& Klein, 2007). We calculated the index using the following formula:

$$
1-\sum_{i=1}^{n} p_{i}^{2}
$$

where $p_{i}$ is individual $i$ 's share of the team's relational resources score (i.e., the sum of the individual's dyadic values divided by the sum of the entire team's dyadic values), and $n$ is equal to the team size. Thus, a team with concentrated relational resources (e.g., two workers with prior experience working together, when all other workers have no experience working together) would have a low value, but a team with distributed, or equal, relational resources across all workers would have a value of $(n-1) / n$.

Distribution of experiential resources. We used the same approach to capture the distribution of experiential resources, substituting each team member's share of the team's experience for relational resources in the prior calculation. The interpretation of the variable is similar to before. A low value corresponds to concentrated experiential resources (e.g., one member with high experience working with a number of team members with low values of experience), and a high value reveals that experiential resources are distributed more equally across team members. Although our measure of experiential resources does not directly capture the heterogeneity in knowledge among team members, studies at the individual level have shown that experience and knowledge correlate (Schmidt et al., 1986; Tesluk \& Jacobs, 1998); therefore, our measures of level of tenure and educational back- 
ground should capture variation in individuals' underlying knowledge.

Control variables. We included four control variables in each model. First, because larger teams may have more trouble with knowledge integration (Hackman, 2002), we controlled for team size. Second, because communication frequency has a demonstrated effect on team performance (Patrashkova \& McComb, 2004), we also controlled for the volume of communications. On survey 2 , respondents were asked to report how many times per week, on average, their team discussed the audit/project in person, by telephone, and via e-mail; responses were averaged to the team level.

Third, because project work that is more demanding could require a greater knowledge integration capability, we controlled for project demands. Partners were asked to rate the focal project as compared to the "average" AuditCo project on the following items using a fivepoint Likert scale: "This audit team has a more complex or technically challenging issue to address," "This audit requires more professional judgment (i.e., forming opinions, not just gathering facts)," and "This audit demands that the ideas of all team members be shared in order to succeed." Project demand items were averaged to create a single score per team $(\alpha=.70)$.

Finally, since some projects might be more important than others and thus garner more focused attention from team members, we asked partners to answer seven questions comparing the current project they were assessing with the average AuditCo project using a five-point Likert scale. Questions included "This client is considered a "high-profile" client within [AuditCo]," "Future engagements with this client depend on the client's satisfaction with this audit," and "This au- dit (and related recommendations in the management letter) will help shape the client's actions and agendas in a material way (e.g., to improve controls procedures, make performance improvements, or change/implement new systems)."

\section{RESULTS}

Table 1 presents means, standard deviations, and correlations for all team-level variables. An inspection of the correlations reveals that relational resources are positively related to a team's knowledge integration capability $(r=.29$, $p<.05$ ), whereas uncertainty is inversely related to it $(r=-.33, p<.05)$. In addition, a team's knowledge integration capability is positively related to team performance $(r=.34, p<.05)$. Results also indicate a lack of association between most of our covariates (specifically, team size, communications volume, and projects' demands) and team performance. Only project importance is significantly related to team performance $(r=.32, p<.05)$.

\section{Resources and Knowledge Integration Capability}

To test our theoretical model depicted in Figure 1 , we conducted ordinary least squares regressions with heteroskedasticity-robust standard errors. The results of our analyses are summarized in Table 2 . We start by examining the first-stage relationships: direct relationships of our independent variables with the knowledge integration capability. Column 1 of Table 2 includes the uncertainty, resource, and control variables. As predicted by Hypothesis 1, the coefficient for relational resources is positive and significant $(\beta=0.32, p<.01)$. However, surprisingly, the coefficient on experiential resources is

TABLE 1

Summary Statistics and Correlations ${ }^{\mathrm{a}}$

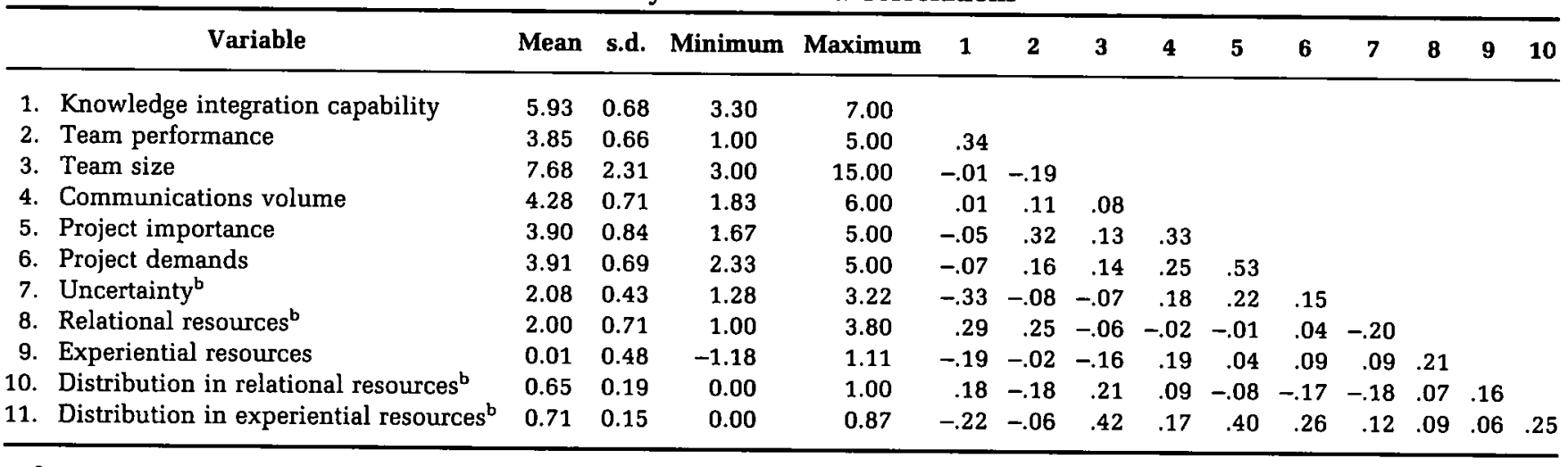

$n=79$.

b In models this variable is centered by subtracting the mean. Values here are before centering. 
TABLE 2

Regression Results for Knowledge Integration Capability and Team Performance ${ }^{a}$

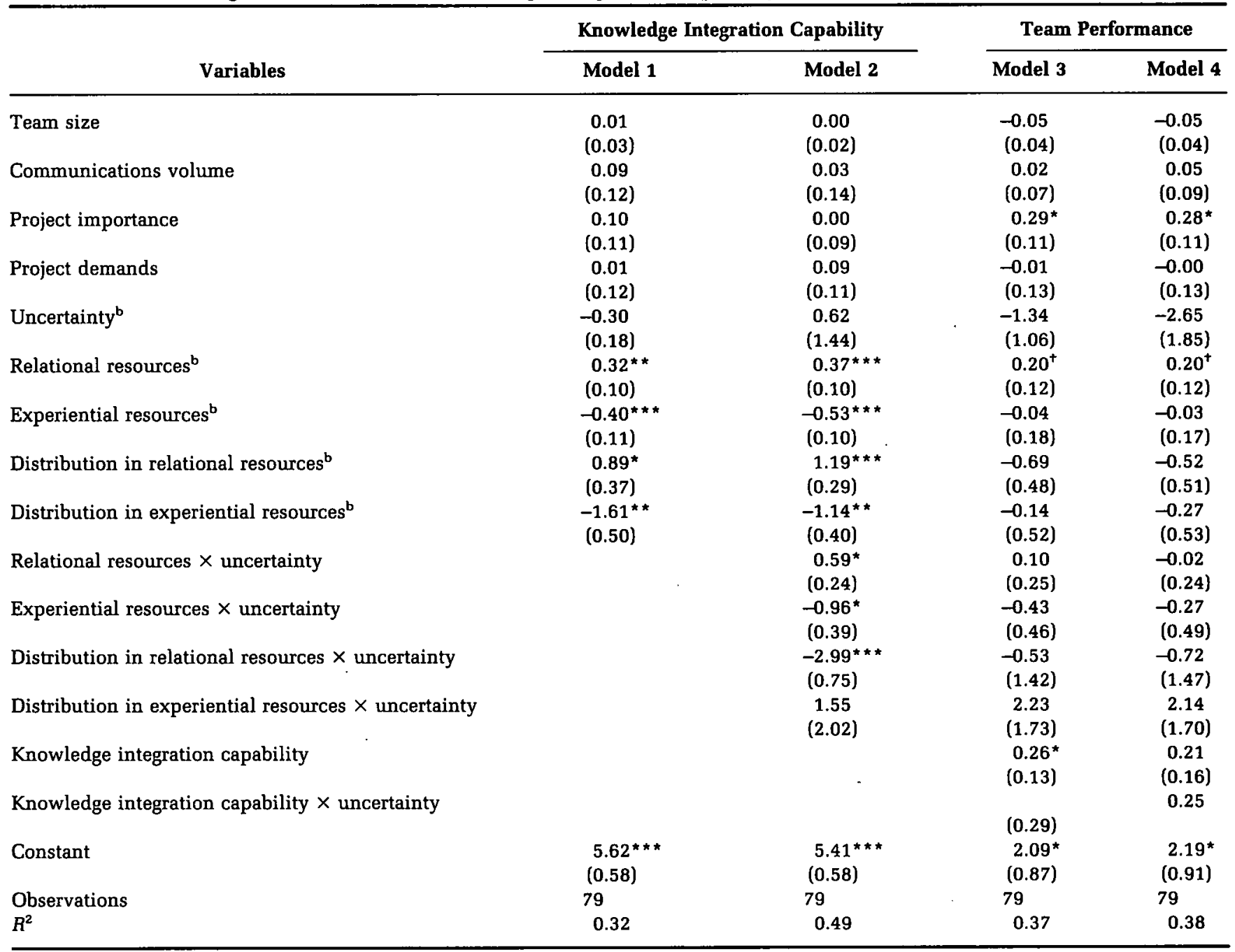

${ }^{a}$ Models are ordinary least squares regressions with heteroskedastic, robust standard errors. $n=79$.

b Variable has been centered.

$+p<.10$

${ }^{\star} p<.05$

$\star * p<.01$

$\star \star \star p<.001$

negative and significant $(\beta=-0.40, p<.001)$, thus not supporting Hypothesis 2. We expand on this unexpected finding in the Discussion section below. Examining the structural resources of a team, we find support for our hypotheses as the coefficient for the distribution of relational resources is positive and significant $(\beta=0.89$, $p<.05$ ) and the coefficient for the distribution of experiential resources is negative and significant $(\beta=-1.61, p<.01)$, supporting Hypotheses 3a and $3 \mathrm{~b}$, respectively. We also checked for curvilinearity of our independent variables and found no evidence of nonlinear relationships. Finally, we calculated variance inflation factors for all models to check for multicollinearity and found all values to be below the recommended threshold of ten (Cohen, Cohen, Aiken, \& West, 2003).

\section{Uncertainty Moderation Analyses}

In column 2 of Table 2 , we add the interaction terms to the model in order to test Hypotheses 4, 5 , and 6 - our moderation hypotheses. In keeping with Hypothesis 4, the coefficient for the interaction of relational resources and uncertainty is positive and significant $(\beta=0.59, p<.05)$. Using the approach of Preacher, Curran, and Bauer (2006) to examine and plot the interaction effect (see column 1 in Table 3 and Figure 2), we found that relational resources were related to a greater 
TABLE 3

Interpreting the Uncertainty Interaction Coefficients ${ }^{\mathrm{a}}$

\begin{tabular}{llll}
\hline \multicolumn{1}{c}{ Test } & \multicolumn{1}{c}{$\begin{array}{c}\text { Relational } \\
\text { Resources } \times \text { Uncertainty }\end{array}$} & $\begin{array}{c}\text { Experiential } \\
\text { Resources } \times \text { Uncertainty }\end{array}$ & $\begin{array}{c}\text { Distribution in Relational } \\
\text { Resources } \times \text { Uncertainty }\end{array}$ \\
\hline $\begin{array}{l}\text { 95\% region of significance } \\
\text { Lower bound }\end{array}$ & -4.12 & & \\
$\quad$ Upper bound & -0.28 & -4.09 & 0.19 \\
$\begin{array}{l}\text { Percentage of projects } \\
\text { Below the lower bound }\end{array}$ & $0 \%$ & -0.27 & 0.86 \\
$\quad$ Between the bounds & $25 \%$ & $0 \%$ & $72 \%$ \\
Above the upper bound & $75 \%$ & $25 \%$ & $24 \%$ \\
Simple slopes & & $75 \%$ & $4 \%$ \\
Low uncertainty & n.s., $p=.33$ & & Significant, $p<.001$ \\
Average uncertainty & Significant, $p<.01$ & n.s., $p=.52$ & Significant, $p<.01$ \\
High uncertainty & Significant, $p<.01$ & Significant, $p<.001$ & n.s., $p=.78$ \\
\hline
\end{tabular}

a The above values were calculated using the Johnson-Neyman technique, following the approach of Preacher and colleagues (2006). These results imply that the coefficient in each column is significant and negative when uncertainty is less than the lower bound, not statistically significant when uncertainty has values between the lower and upper bound, and significant and positive when uncertaint $y$ has a value greater than the upper bound.

knowledge integration capability when uncertainty was high or at average values $(p<.01$ in both cases) but were not associated with a greater knowledge integration capability when uncertainty was low ( $p=.21$ ).

Shifting to the interaction of a team's experiential resources and uncertainty, we find that it is nega- tive and significant $(\beta=-0.96, p<.05)$ : highe: team experiential resources relate to a lower knowledge integration capability in the face of uncertainty, supporting Hypothesis 5. Again using the Preacher et al. (2006) approach (column 2 of Table 3 and Figure 3), we found that team experiential resources were related to less knowledge integra-

FIGURE 2

Interaction of Relational Resources and Uncertainty on Knowledge Integration Capability

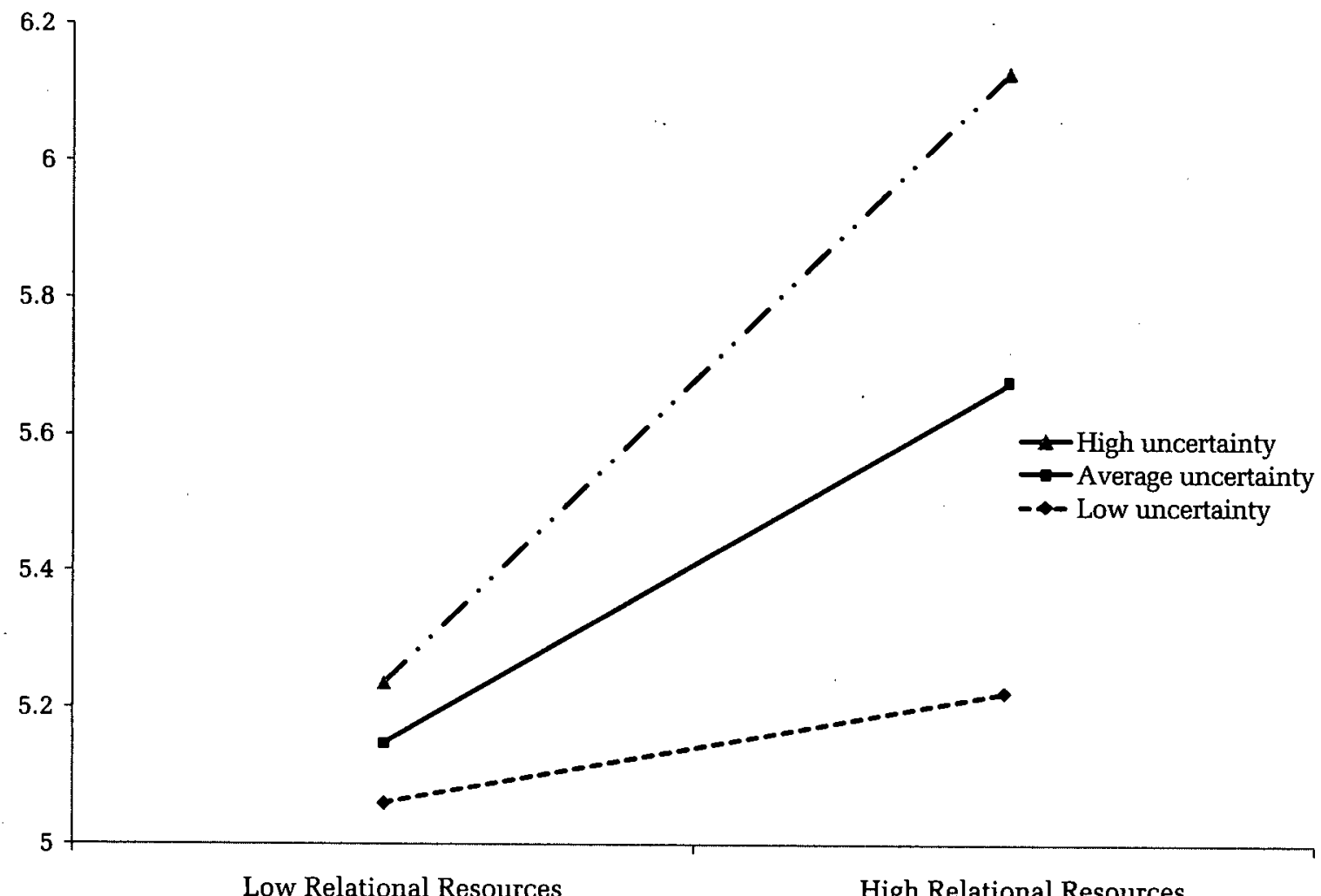


FIGURE 3

Interaction of Experiential Resources and Uncertainty on Knowledge Integration Capability

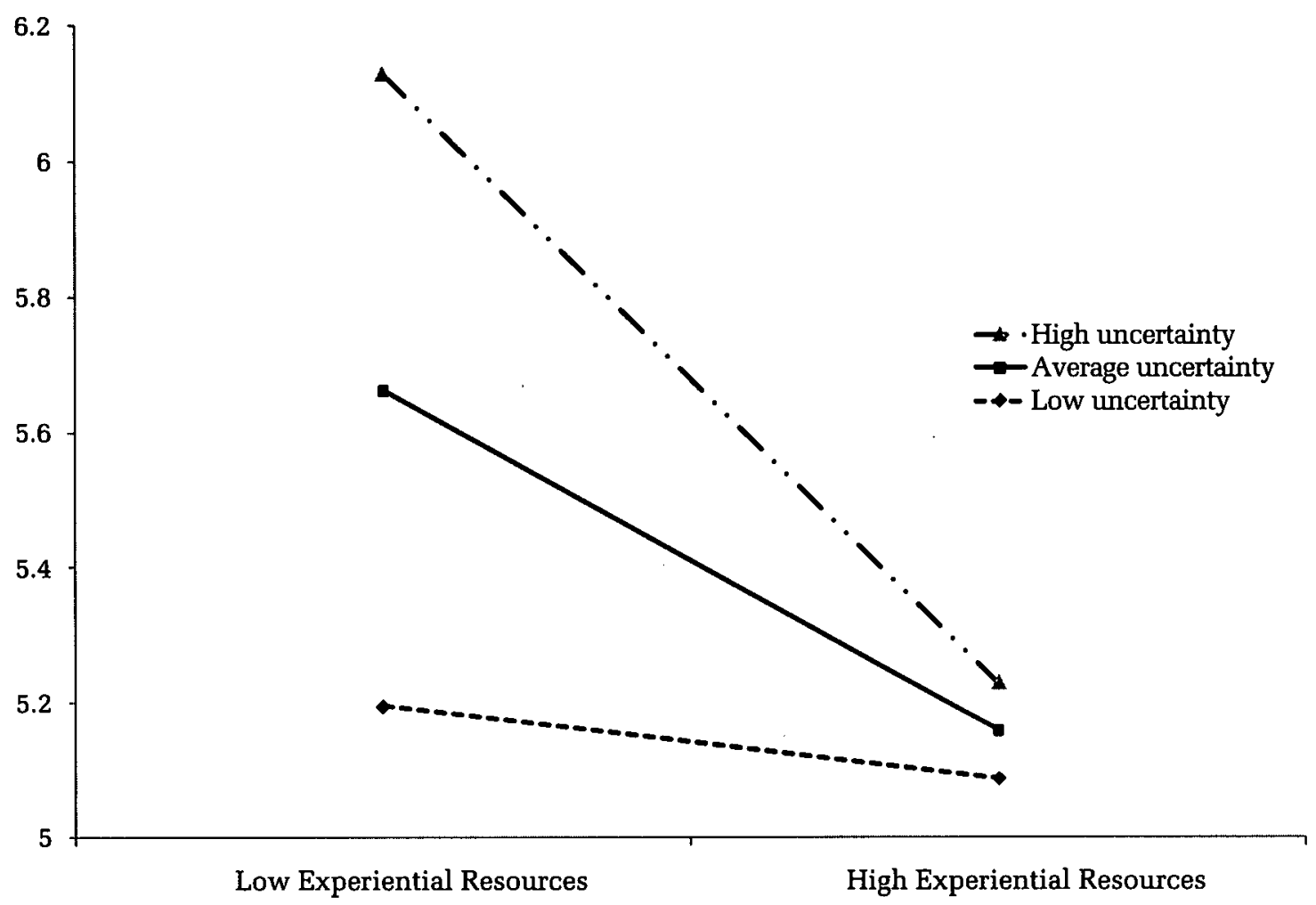

tion when uncertainty was high or at average values ( $p<.001$ and $p<.01$, respectively) but were not associated with the knowledge integration capability when uncertainty was low $(p=.51)$.

Turning to teams' structural resources, we examine the coefficient for the interaction of the distribution of relational resources and uncertainty, finding it to be negative and significant ( $\beta=-2.99, p<.001$ ); thus, Hypothesis $6 \mathrm{a}$ is not supported. Although more evenly distributed relational resources are, on average, related to greater knowledge integration, we see no additional benefit when teams are faced with uncertain tasks, but instead find evidence for the opposite effect. The Preacher et al. analysis and plot (column 3 of Table 3 and Figure 4) show that for low and average values of uncertainty, increasing the distribution of relational resources across team members is related to a greater knowledge integration capability $(p<.001$ and $p<.01$, respectively). However, under conditions of high uncertainty, changing the distribution of relational resources in a team does not change the relationship to the knowledge integration capability $(p=.61)$. We note, however, that at very high levels of uncertainty-that is, for the top 4 percent of projects-there is a negative relationship with the knowledge integration capability.
Regarding our last moderation hypothesis, we find that the coefficient for the interaction of the distribution of experiential resources and uncertainty is positive but not significant, thus failing to support Hypothesis $6 \mathrm{~b}$.

\section{Team Performance}

Hypothesis 7 predicts that a knowledge integration capability will positively relate to team performance. As shown in column 3 of Table 2, we find support for this hypothesis, as the coefficient for the knowledge integration capability is positive and statistically significant. A one standard deviation increase in the knowledge integration capability relates to a 4.6 percent increase in team performance.

\section{Moderated Mediation Hypothesis}

Our theoretical model (see Figure 1) corresponds to moderated mediation, as the relationship of our relational, experiential, and structural resources with the mediator, knowledge integration capability, is moderated by uncertainty, and the mediator is directly related to project performance. To test for moderated mediation, we followed the approach of Preacher, Rucker, and Hayes (2007) and 
FIGURE 4

Interaction of Distribution in Relational Resources and Uncertainty on Knowledge Integration Capability

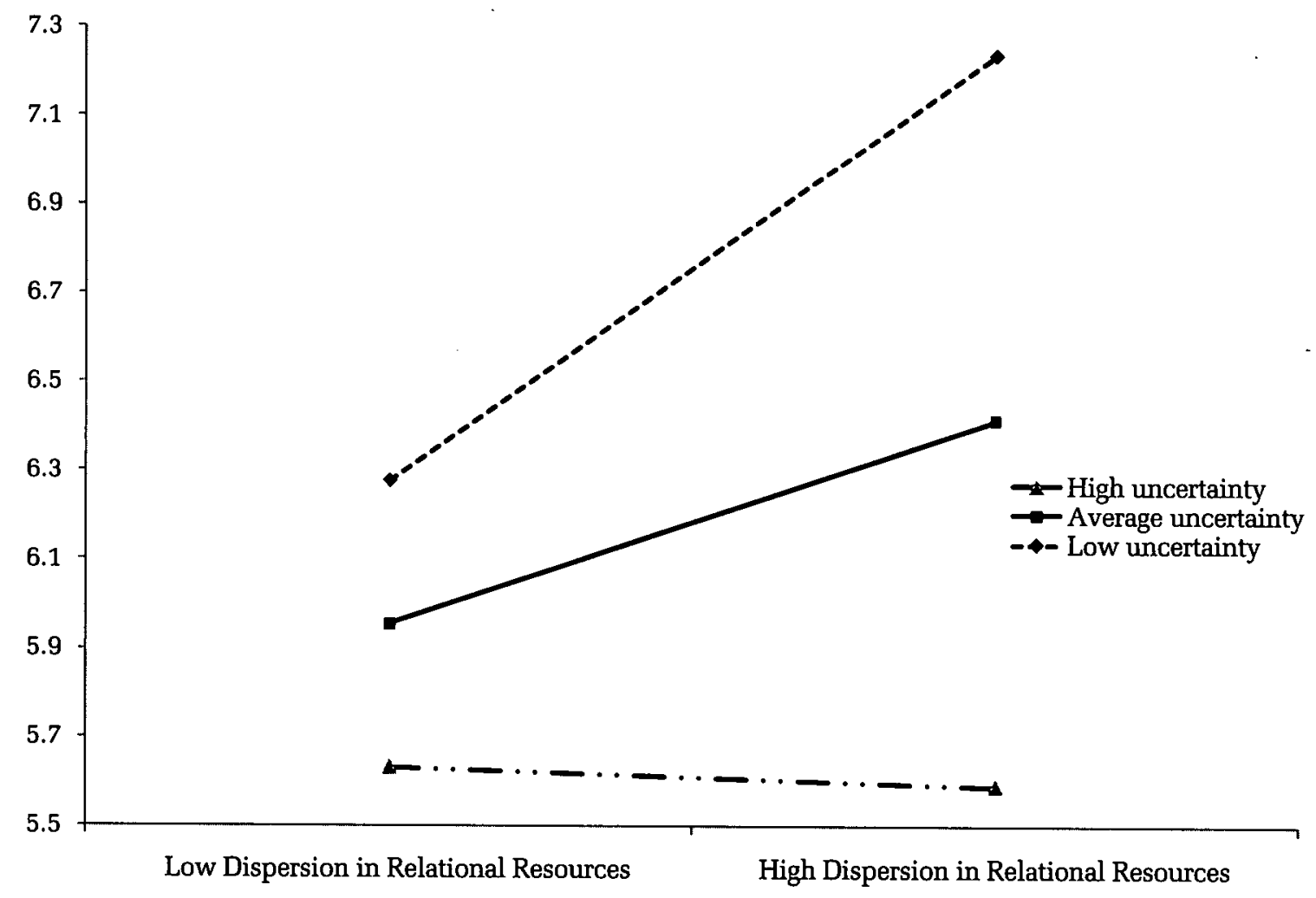

used a bootstrap technique to test the magnitude of each indirect relationship at high and low values of the moderator (plus and minus one standard deviation, respectively). If the magnitude of the indirect relationship differs significantly from zero, then mediation has occurred.

We tested for moderated mediation separately for each of our four independent variables and for the moderator, uncertainty. The results for the indirect effects, reported in Table 4, support the moderated mediation hypothesis for relational resources, experiential resources, and the distribution of relational resources. Also, in column 4 of Table 2, we include the interaction between knowledge integration capability and uncertainty; the variable is not statistically significant.
This finding is consistent with our theoretica: model, which proposes that moderation occurs ir the first stage, not the second (Edwards \& Lambert, 2007). Together, these results support Hypothesis 8 and indicate that knowledge integration capability mediates the moderating relationship of task uncertainty on relational anc experiential resources, and the distribution 0 relational resources, but not the distribution o:experiential resources with team performance.

\section{DISCUSSION}

Using multisource data concerning 79 client-facing project teams in a professional services firm, we find that both relational resources and the structure

TABLE 4

Moderated Mediation Tests

\begin{tabular}{|c|c|c|c|c|c|c|c|c|}
\hline & \multirow{2}{*}{\multicolumn{2}{|c|}{$\begin{array}{c}\text { Relational } \\
\text { Resources }\end{array}$}} & \multirow{2}{*}{\multicolumn{2}{|c|}{$\begin{array}{c}\begin{array}{c}\text { Experiential } \\
\text { Resources }\end{array} \\
\text { Uncertainty }\end{array}$}} & \multirow{2}{*}{\multicolumn{2}{|c|}{$\begin{array}{c}\begin{array}{c}\text { Distribution in } \\
\text { Relational Resources }\end{array} \\
\text { Uncertainty }\end{array}$}} & \multirow{2}{*}{\multicolumn{2}{|c|}{$\begin{array}{c}\begin{array}{c}\text { Distribution in } \\
\text { Experiential Resources }\end{array} \\
\text { Uncertainty }\end{array}$}} \\
\hline & & & & & & & & \\
\hline & Low & High & Low & High & Low & High & Low & High \\
\hline Indirect effect & 0.02 & $0.12^{\star}$ & -0.01 & $-0.16^{\star}$ & $0.64^{\star}$ & -0.07 & -0.08 & -0.47 \\
\hline
\end{tabular}

${ }^{\star} p<.05$ 
of those resources aid the development of teams' knowledge integration capability, but both experiential resources and the structure of those resources detract from development of that capability. We also find that uncertainty plays an important moderating role in these relationships. Relational resources help teams develop their knowledge integration capability in the face of uncertainty, although the structure of relational resources (i.e., their distribution within a team) only improves knowledge integration capability under average and low uncertainty. In contrast, high experiential resources are related to a lower knowledge integration capability in the face of uncertainty.

Our finding regarding the main association with experiential resources and a team's knowledge integration capability is counter to our hypothesis. Although we had hypothesized that higher levels of experiential resources would aid in the development of teams' knowledge integration capability, we found that they actually impeded such development. On reflection, we believe this result can be understood by considering the context of our study and our uncertainty moderation result. In particular, we predicted and found that the interaction of uncertainty with experiential resources would detract from knowledge integration capability development. We derived this hypothesis by using a dynamic capabilities perspective, arguing that experiential resources might lead to rigidities that inhibit the efficiency, collaborativeness, and validity of team members' communication. Although some projects in our sample did encounter more uncertainty than others, and thus we found a significant interaction relationship, all project teams were operating in dynamic and uncertain environments. If our study had examined teams executing simple procedural tasks, then our existing Hypothesis 2 might have been supported. However, since all teams faced uncertainty, it is possible that rigidities due to higher experiential resources inhibited teams on all projects in the study. Future work should investigate whether these relationships differ in varying settings (e.g., procedural tasks) and also examine ways in which teams facing uncertain tasks can overcome the possible problems of high levels of experiential resources.

The other unexpected result we found is that the distribution of relational resources is related to greater knowledge integration capability development for teams facing low or medium levels of uncertainty, but not for teams facing high levels of uncertainty (and only for teams facing the highest 3 percent of uncertainty does it detract from capability development). It is possible that when conditions are highly uncertain, a smaller number of very deep dyadic relationships may be as effective as a greater number of more shallow dyadic relationships, holding the total relational resources constant (cf. Hansen, 1999). Future work should explore this hypothesis further and investigate underlying mechanisms.

\section{Theoretical Contributions}

Organizations increasingly deploy teams to deliver innovative outputs. However, these teams often fail to meet expectations because they are unable to capitalize on their resources (Hackman \& Katz, 2010; Ilgen et al., 2005). Drawing from the firm-level resource-based view, we examined how teams can achieve high levels of performance by building a dynamic knowledge integration capability. Specifically, we explored how different types of resources relate to the development of the capability and how task uncertainty moderates this process. In so doing, we make several contributions to both the teams and strategy literatures.

First, with respect to teams' research, we build on a growing body of work that examines why some groups are more effective than others (Hackman \& Katz, 2010; Ilgen et al., 2005). In particular, we propose that a team knowledge integration process is one key to this puzzle. Kozlowski et al. (1999) theorized that teams completing complex, rapidly changing work must integrate their knowledge in an ongoing process of mutual adjustment, while the work takes place, to be successful (Thompson, 1967; Van de Ven et al., 1976). Drawing on the strategy literature, we are able to conceptualize how this takes place-through the dynamic knowledge integration capability-and then measure development of the capability as well as its association with team performance.

The capability perspective aids in gaining further understanding of knowledge integration, and by building on it, this article contributes to a theoretical framework within which future investigations of knowledge-based teamwork and team performance can be pursued more fruitfully and systematically. Recent work on teams has underscored challenges with the team literature's dominant research framework of input-process-output (I-P-O; Hackman \& Katz, 2010; Ilgen et al., 2005; Marks, Mathieu, \& Zaccaro, 2001). Proposed changes from this framework include modeling simultaneous I-P-O cycles as well as sequential cycles that note the direct linkages from 
output in one temporal episode to input in another. In addition to these important extensions, the focus in the capabilities literature on repeatability (e.g., Teece et al., 1997; Zollo \& Winter, 2002; Sirmon et al., 2007) highlights not only that output can provide feedback loops to a next cycle's input (as in the input-mediator-output-input [IMOI] model in Ilgen et al. [2005]), but also that feedback loops may exist between the inputs and the processes. In other words, ongoing, repeated interactions shape team processes and eventually team performance. Our study is a first step toward understanding how inputs and processes may interact. By explicitly modeling this feedback loop, team researchers can develop more nuanced and impactful theory.

Our study also contributes to the literature on teams by building on the growing body of work on relational resources and fluid teams (e.g., Espinosa et al., 2007; Huckman et al., 2009; Reagans et al., 2005). We find that relational resources not only are related to the development of the knowledge integration capability, but also are particularly valuable in situations characterized by high uncertainty. Relational resources may help team members speak the same language (Cramton, 2001; Monteverde, 1995), develop a shared knowledge regarding who knows what (Lewis et al., 2005), and build interpersonal comfort in risk taking (Edmondson, 1999; Gruenfeld et al., 1996). Future work should seek to examine these different mechanisms simultaneously to understand each one's relative contribution to our results.

Finally, although reviews of the team literature highlight the increasing uncertainty that teams encounter, they also note that little empirical work has directly studied uncertainty in the field (Hackman \& Katz, 2010; Ilgen et al., 2005; Kozlowski et al., 1999). In this article, we examine a dynamic, complex knowledge work setting and directly measure task uncertainty. In so doing, we shed light on the important role uncertainty plays in the development of a knowledge-integration capability.

Second, our study also contributes to work in the strategy field. Studies in strategic management increasingly focus on the microfoundations of capability, the study of which also requires study of organization members and their interactions (Argote \& Ingram, 2000; Helfat, 2000). To avoid recreating the wheel, we must draw upon the wealth of relevant findings about organizational behavior. By grounding our study in the team literature, we are able to robustly measure one dynamic capability, thereby extending prior theoretical and qualitative work that has exam- ined dynamic capabilities (e.g., Eisenhardt \& Martin, 2000). With this approach, we can gain insight into the microfactors shaping the development of a dynamic capability.

Our study offers guidance as to the types of resource portfolios to build, along with insight into how and where to deploy resources most effectively within a team. Early work in the resource-based view tradition focused attention on characteristics of the underlying resources (e.g., are they valuable, rare, inimitable, or nonsubstitutable?) and their relationship to creating competitive advantage (Barney, 1991). Subsequent work has noted that performance is a function not merely of having resources, but also of "bundling" and combining those resources (Eisenhardt \& Martin, 2000; Sirmon et al., 2007; Teece et al., 1997). We support this latter perspective, finding that resources are related to bundling in nonobvious ways. We find that having resources is actually a double-edged sword: the need for combining resources, in our case through knowledge integration, means that depending on the type of resource involved, more of the resource might aid performance (e.g., in the case of relational resources) or harm it (e.g., in the case of experiential resources). Future work should continue to integrate research in strategic management and organizational behavior to increase scholars' understanding of the complex ways in which various resources are transformed into performance.

\section{Limitations and Future Directions}

Several limitations of this work should be noted. The first concerns possible same-source bias. We were able to use a separate evaluator for one dependent variable (i.e., a partner in each sampled firm evaluated team performance); however, the same individuals (i.e., team members) were used to evaluate both the knowledge integration capability of their team and the independent variables, uncertainty and relational resources. We chose to have team members evaluate the knowledge integration capability since they were closest to the projects and in the best position to evaluate conversations' perceived quality; outsiders might interpret some of the quality as merely noisy signals. Additionally, we mitigated the risk of bias as much as possible by collecting the independent variables at the start of the projects and our communication quality evaluation at the projects' ends. Nevertheless, we cannot categorically rule out the possibility of bias. 
Second, we restricted ourselves in this study to teams with a life span of several months, as opposed to several years. We think this shorter time period matches the reality of many project-based organizations (Edmondson \&. Nembhard, 2009; Huckman et al., 2009) and offers a considerable advantage over the time periods captured in most lab-based studies, yet future work should explore these dynamics in teams that stay together for longer time periods. Third, taking our survey sample from a single firm raises questions of generalizability. The relatively large number of teams $(n=79)$ and inclusion of both audit and consulting projects should ameliorate the issue to some degree. Nevertheless, future work should explore our findings both in other knowledge-intensive firms and in other settings.

Fourth, we referred to several microprocesses in developing hypotheses about how resources that teams possess lead to knowledge-integration capability development. These microprocesses included both cognitive (e.g., ability to process information) and relational factors (e.g., interpersonal trust, social acceptance). Future research could examine in more detail relationships in our model by identifying specific micromediators that drive them (see Marks et al., 2001).

Fifth, our work focused inwardly, on the knowledge resources available to a team. However, team members regularly obtain information and acquire knowledge from outside sources. Further work could investigate the role of predictors and outcomes at both the individual and team levels, including behaviors such as "boundary spanning" (Ancona \& Caldwell, 1990), which aids performance by complementing internal resources with those outside a team. In addition, we acknowledge that we have restricted our investigation to three types of resources that were demonstrated to be important to the domain of dynamic capabilities. Future researchers could broaden the scope of this research model by including additional resources. Further, though we modeled structural resources by examining the concentration and distribution of such resources, additional insight may be gained by considering other configurations of resources in a team. Altogether, such investigation would deepen understanding of how teams can effectively integrate knowledge resources and achieve high levels of performance.

Another limitation of our research is its focus on only one moderator for the relationship between relational, experiential, and structural resources and a team's knowledge integration capabilitynamely, task uncertainty. Other moderators related to the nature of the project the team is working on, or situational factors that may impact the work (e.g., time pressure), are also certainly important, however. We hope our work will inspire future investigations into the effects of these and other moderators.

Seventh, we evaluate experiential resources using quantitative measures (e.g., organizational tenure) as opposed to qualitative measures (e.g., different task types). Our measure is grounded in the prior literature (e.g., Hitt et al., 2006), and previous research indicates that increasing experience leads to greater knowledge (Schmidt et al., 1986; Tesluk \& Jacobs, 1998). Future work should explore how experience accumulates across different task types as well as how multifunctional teams affect the building of a knowledge integration capability.

Finally, another fruitful venue for future research is the role of leadership in managing teams with different levels and distributions of knowledge resources. We have suggested that it is critical for teams to build a capability to integrate relational and experiential resources. Team leaders may play an important role in the process of integration. Future research examining this possibility would further understanding of the boundary conditions of our theoretical model.

\section{Practical Implications and Conclusion}

Our research offers valuable practical insights for both team leaders and team members. First, our findings support a relationship between knowledge integration capability and team performance. Our theorizing suggests that the challenges of integrating distributed resources are not simply solved by good communication, but rather that when teams develop a reliable, systematic process with communications that are efficient, collaborative, and valid, it is possible to build a capability for knowledge integration. Second, our findings suggest that managers should give special attention to developing the knowledge integration capability in more experienced teams. Instead of aiding knowledge integration, higher levels of experiential resources may actually detract from it. Rather than simply trusting that an experienced team will "take care of business," managers may need to allocate additional attention to ensuring that knowledge integration does not suffer, especially as uncertainty increases. Finally, our results place a potentially powerful lever in the hands of managers. Prior work on relational resources has generally suggested that more is better; the present study, however, identifies potential for some targeted intervention. Namely, when teams face higher uncertainty, relational re- 
sources are particularly valuable, as they may enable the teams to build their knowledge integration capability. Managers forming teams to face uncertain tasks should therefore aim to increase both the overall level of relational resources and the distribution of such resources in each team. Given the difficulties of replicating relational resources by moving an entire team, managers can work to build a sustainable competitive advantage through especially careful allocation of individuals to teams in order to achieve higher levels of relational resources.

In conclusion, this article advances theory by investigating how teams can develop a dynamic knowledge integration capability. We find that development of this capability allows some teams to convert members' knowledge resources into higher performance while others fail to develop this capability and therefore leave some resources untapped. Altogether, we hope that by bringing a resourcebased approach to teams' research, we are helping to build a productive bridge for ongoing dialogue between the fields of strategic management and organizational behavior.

\section{REFERENCES}

Adner, R., \& Helfat, C. 2003. Dynamic managerial capabilities and corporate effects. Strategic Management Journal, 24: 1011-1027.

Aiken, L. S., \& West, S. G. 1991. Multiple regression: Testing and interpreting interactions. Thousand Oaks, CA: Sage.

Alvesson, M. 1993. Organizations as rhetoric: Knowledge-intensive firms and the struggle with ambiguity. Journal of Management Studies, 30: 997-1015.

Ancona, D. G., \& Caldwell, D. F. 1990. Improving the performance of new product teams. Research Technology Management, 33(March-April): 25-29.

Apker, J., Propp, K. M., Ford, W. S., \& Hofmeister, N. 2006. Collaboration, credibility, compassion, and coordination: Professional nurse communication skill sets in health care team interactions. Journal of Professional Nursing, 22: 180-189.

Argote, L. 1999. Organizational learning: Creating, retaining and transferring knowledge. Norwell, MA: Kluwer.

Argote, L., \& Ingram, P. 2000. Knowledge transfer: A basis for competitive advantage in firms. Organizational Behavior and Human Decision Processes, 82: 150-169.

Argote, L., Turner, M. E., \& Fichman, M. 1989. To centralize or not to centralize: The effects of uncertainty and threat on group structure and performance. Or- ganizational Behavior and Human Decision Processes, 43: 58-74.

Austin, J. R. 2003. Transactive memory in organizational groups: The effects of content, consensus, specialization, and accuracy on group performance. Journal of Applied Psychology, 88: 866-878.

Barney, J. B. 1991. Firm resources and sustained competitive advantage. Journal of Management, 17: 99120.

Bendersky, C., \& Hays, N. A. 2012. Status conflict in groups. Organization Science, 23: 323-340.

Blau, P. M. 1977. Inequality and heterogeneity. New York: Free Press.

Bunderson, J. S. 2003. Recognizing and utilizing expertise in work groups: A status characteristics perspective. Administrative Science Quarterly, 48: 557591.

Bunderson, J. S., \& Sutcliffe, K. M. 2002. Comparing alternative conceptualizations of functional diversity in management teams: Process and performance effects. Academy of Management Journal, 45: 875893.

Carlile, P. R., \& Rebentisch, E. S. 2003. Into the black box: The knowledge transformation cycle. Management Science, 49: 1180-1195.

Clark, H. H., \& Marshall, C. R. 1981. Definite reference and mutual knowledge. In A. K. Joshi, B. L. Webber, \& I. A. Sag (Eds.), Elements of discourse understanding: 10-63. New York: Cambridge University Press.

Cohen, J., Cohen, P., Aiken, L. S., \& West, S. G. 2003. Applied multiple regression-Correlation analysis for the behavioral sciences (3rd ed.). Mahwah, NJ: Erlbaum.

Coleman, J. S. 1988. Social capital in the creation of human capital. American Journal of Sociology, 94: S95-S120.

Cramton, C. D. 2001. The mutual knowledge problem and its consequences in geographically dispersed teams. Organization Science, 12: 346-371.

Cronin, M. A., \& Weingart, L. R. 2007. Representational gaps, information processing, and conflict in functionally diverse teams. Academy of Management Review, 32: 761-773.

Cummings, J. N. 2004. Work groups, structural diversity, and knowledge sharing in a global organization. Management Science, 50: 352-364.

Dierickx, I., \& Cool, K. 1989. Asset stock accumulation and the sustainability of competitive advantage. Management Science, 35: 1504-1511.

Dimov, D., \& Shepherd, D. A. 2005. Human capital theory and venture capital firms: Exploring "home runs" 
and "strike outs." Journal of Business Venturing, 20: 1-21.

Dirks, K. T. 1999. The effects of interpersonal trust on work group performance. Journal of Applied Psy. chology, 84: 445-455.

Drach-Zahavy, A., \& Somech, A. 2001. Understanding team innovation: The role of team processes and structures. Group Dynamics: Theory, Research, and Practice, 5: 111-123.

Edmondson, A. C., \& Nembhard, I. A. 2009. Product development and learning in project teams: The challenges are the benefits. Journal of Product Innovation Management, 26: 123-138.

Edmondson, A. 1999. Psychological safety and learning behavior in work teams. Administrative Science Quarterly, 44: 350-353.

Edwards, J. R., \& Lambert, L. S. 2007. Methods for integrating moderation and mediation: A general analytical framework using moderated path analysis. Psychological Methods, 12: 1-22.

Eisenhardt, K. M., \& Martin, J. A. 2000. Dynamic capabilities: What are they? Strategic Management Journal, 21: 1105-1121.

Espinosa, J. A., Slaughter, S. A., Kraut, R. E., \& Herbsleb, J. D. 2007. Familiarity, complexity, and team performance in geographically distributed software development. Organization Science, 18: 613630.

Galbraith, J. 1973. Designing complex organizations. Reading, MA: Addison-Wesley.

Gardner, H. K. 2012 Performance pressure as a doubleedged sword: Enhancing team motivation but undermining the use of team knowledge. Administrative Science Quarterly, 57: 1-46.

Gersick, C. J., \& Hackman, J. R. 1990. Habitual routines in task-performing groups. Organizational Behavior and Human Decision Processes, 47: 65-97.

Gibson, C., Waller, M. J., Carpenter, M., \& Conte, J. M. 2007. Antecedents, consequences, and moderators of time perspective heterogeneity for knowledge management in MNO teams. Journal of Organizational Behavior, 28: 1005-1034.

Gino, F., Argote, L., Miron-Spektor, E., \& Todorova, G. 2010. First, get your feet wet: The effects of learning from direct and indirect experience on team creativity. Organizational Behavior and Human Decision Processes, 111: 93-101.

Gladstein, D. L., \& Reilly, N. P. 1985. Group decision making under threat: The tycoon game. Academy of Management Journal, 28: 613-627.

Goodman, P. S., \& Leyden, D. P. 1991. Familiarity and group productivity. Journal of Applied Psychology, 76: 578-586.

Grant, R. M. 1996. Toward a knowledge-based theory of the firm. Strategic Management Journal, 17: 109122.

Gruenfeld, D. H., Mannix, E. A., Williams, K. Y., \& Neale, M. A. 1996. Group composition and decision making: How member familiarity and information distribution affect process and performance. Organizational Behavior and Human Decision Processes, 67: 1-15.

Gruenfeld, D. H., Martorana, P. V., \& Fan, E. T. 2000. What do groups learn from their worldliest members? Direct and indirect influence in dynamic teams. Organizational Behavior and Human Decision Processes, 82: 45-59.

Haas, M. R., \& Hansen, M. T. 2007. Different knowledge, different benefits: Toward a productivity perspective on knowledge sharing in organizations. Strategic Management Journal, 28: 1133-1153.

Hackman, J. R. 2002. Leading teams: Setting the stage for great performances. Boston: HBS Press.

Hackman, J. R., \& Katz, N. 2010. Group behavior and performance. In S. T. Fiske, D. T. Gilbert, \& G. Lindzey (Eds.), Handbook of social psychology (5th ed.): 1208-1251. New York: Wiley.

Hackman, J. R., \& Walton, R. E. 1986. Leading groups in organizations. In P. S. Goodman (Ed.), Designing effective work groups: 72-119. San Francisco: Jossey-Bass.

Hambrick, D. 1994. Top management groups: A conceptual integration and reconsideration of the "team" label. In B. M. Staw \& L. L. Cummings (Eds.), Research in organizational behavior, vol. 16: 171213. Greenwich, CT: JAI.

Hansen, M. T. 1999. The search-transfer problem: The role of weak ties in sharing knowledge across organization subunits. Administrative Science Quarterly, 44: 82-111.

Harrison, D. A., \& Klein, K. J. 2007. What's the difference? Diversity constructs as separation, variety, or disparity in organizations. Academy of Management Review, 32: 1199-1228.

Helfat, C. E. 2000. Guest editor's introduction to the special issue: The evolution of firm capabilities. Strategic Management Journal, 21: 955-959.

Helfat, C., \& Peteraf, M. A. 2003. The dynamic resourcebased view: Capability lifecycles. Strategic Management Journal, 24: 997-1010.

Hitt, M. A., Bierman, L., Uhlenbruck, K., \& Shimizu, K. 2006. The importance of resources in the internationalization of professional service firms: The good, the bad, and the ugly. Academy of Management Journal, 49: 1137-1157. 
Hoegl, M., \& Gemuenden, H. G. 2001. Teamwork quality and the success of innovative projects: A theoretical concept and empirical evidence. Organization Science, 12: 435-449.

Hofmann, D. A., Lei, Z., \& Grant, A. M. 2009. Seeking help in the shadow of a doubt: The sensemaking processes underlying how nurses decide whom to ask for advice. Journal of Applied Psychology, 94: 1261-1274.

Hollingshead, A. B. 1998. Retrieval processes in transactive memory systems. Journal of Personality and Social Psychology, 74: 659-671.

Huckman, R. S., \& Staats, B. R. 2011. Fluid tasks and fluid teams: The impact of diversity in experience and team familiarity on team performance. Manufacturing and Service Operations Management, 13: $310-328$.

Huckman, R. S., Staats, B. R., \& Upton, D. M. 2009. Team familiarity, role experience, and performance: Evidence from Indian software services. Management Science, 55: 85-100.

Ilgen, D. R., Hollenbeck, J. R., Johnson, M., \& Jundt, D. 2005. Teams in organizations: From input-processoutput models to IMOI models. S. Fiske, D. L. Schacter, \& A. Kasdin (Eds.), Annual review of psychology, vol. 56: 517-543. Palo Alto, CA: Annual Reviews.

Jehn, K. A., \& Mannix, E. A. 2001. The dynamic nature of conflict: A longitudinal study of intragroup conflict and group performance. Academy of Management Journal, 44: 238-251.

Jehn, K. A., Northcraft, G. B., \& Neale, M. A. 1999. Why differences make a difference: A field study of diversity, conflict, and performance in workgroups. Administrative Science Quarterly, 44: 741-763.

Kane, A. A., Argote, L., \& Levine, J. M. 2005. Knowledge transfer between groups via personnel rotation: Effects of social identity and knowledge quality. Organizational Behavior and Human Decision Processes, 96: 56-71.

Klein, K. J., \& Kozlowski, S. W. J. (Eds.). 2000. Multilevel theory, research and methods in organizations. San Francisco: Jossey-Bass.

Kogut, B., \& Zander, U. 1992. Knowledge of the firm, combinative capabilities, and the replication of technology. Organization Science, 3: 383-397.

Kooij-de Bode, H. J. M., van Knippenberg, D., \& van Ginkel, W. P. 2010. Good effects of bad feelings: Negative affectivity and group decision-making. British Journal of Management, 21: 375-392.

Kozlowski, S. W. J., Gully, S. M., Nason, E. R., \& Smith, E. M. 1999. Developing adaptive teams: A theory of compilation and performance across levels and time. In D. R. Ilgen \& E. D. Pulakos (Eds.), The changing nature of performance: 240-292. San Francisco: Jossey-Bass.

Krauss, R. M., \& Fussell, S. R. 1990. Mutual knowledge and communicative effectiveness. In J. Galegher, R. E. Kraut, \& C. Egido (Eds.), Intellectual teamwork: Social and technical bases of collaborative work: 111-145. Hillsdale, NJ: Erlbaum.

Larson, J. R., Christensen, C., Abbott, A. S., \& Franz, T. M. 1996. Diagnosing groups: Charting the flow of information in medical decision-making teams. Journal of Personality and Social Psychology, 71: 315-330.

Lau, D. C., \& Murnighan, J. K. 1998. Demographic diversity and fault lines: The compositional dynamics of organizational groups. Academy of Management Review, 23: 325-240.

Lau, D. C., \& Murnighan, J. K. 2005. Interactions within groups and subgroups: The effects of demographic faultlines. Academy of Management Journal, 48: 645-659.

Laughlin, P. R., Bonner, B. L., \& Miner, A. G. 2002. Groups perform better than the best individuals on letters-tonumbers problems. Organizational Behavior and Human Decision Processes, 88: 605-620.

Leathers, D. G. 1972. Quality of group communication as a determinant of group product. Speech Monographs, 39: 166-173.

Leik, R. K. 1963. Instrumentality and emotionality in family interaction. Sociometry, 26: 131-145.

Leonard-Barton, D. 1992. Core capabilities and core rigidities: A paradox in managing new product development. Strategic Management Journal, 13: 111125.

Levitt, B., \& March, J. G. 1988. Organizational learning. In W. R. Scott (Ed.), Annual review of sociology, vol. 14: 319-340. Palo Alto, CA: Annual Reviews.

Lewis, K. 2003. Measuring transactive memory systems in the field: Scale development and validation. Journal of Applied Psychology, 88: 587-604.

Lewis, K. 2004. Knowledge and performance in knowledge-worker teams: A longitudinal study of transactive memory systems. Management Science, 50: 1519-1533.

Lewis, K., Lange, D., \& Gillis, L. 2005. Transactive memory systems, learning, and learning transfer. Organization Science, 16: 581-598.

Liang, D. W., Moreland, R., \& Argote, L. 1995. Group versus individual training and group performance: The mediating role of transactive memory. Personality and Social Psychology Bulletin, 21: 384-393.

Littlepage, G., Robison, W., \& Reddington, K. 1997. Effects of task experience and group experience on group performance, member ability, and recognition 
of expertise. Organizational Behavior and Human Decision Processes, 69: 133-147.

March, J. G. 1991. Exploration and exploitation in organizational learning. Organization Science, 2: 71-87.

Marks, M. A., Mathieu, J. E., \& Zaccaro, S. J. 2001. A temporally based framework and taxonomy of team processes. Academy of Management Review, 26: 356-376.

Mathieu, J. E., Goodwin, G. F., Heffner, T. S., Salas, E., \& Cannon-Bowers, J. A. 2000. The influence of shared mental models on team process and performance. Journal of Applied Psychology, 85: 273-283.

Monteverde, K. 1995. Technical dialog as an incentive for vertical integration in the semiconductor industry. Management Science, 41: 1624-1638.

Moreland, R. L., \& Myaskovsky, L. 2000. Exploring the performance benefits of group training: Transactive memory or improved communication? Organizational Behavior and Human Decision Processes, 82: 117-133.

Nelson, R. R., \& Winter, S. G. 1982. An evolutionary theory of economic change. Cambridge, U.K.: Harvard University Press.

Orengo Castellá, V., Zornoza Abad, A. M., Prieto Alonso, F., \& Peiro Silla, J. M. 2000. The influence of familiarity among group members, group atmosphere and assertiveness on uninhibited behavior through three different communication media. Computers in $\mathbf{H u}$ man Behavior, 16: 141-159.

Patrashkova, R. R., \& McComb, S. A. 2004. Exploring why more communication is not better: Insights from a computational model of cross-functional teams. Journal of Engineering and Technology Management, 21: 83-114.

Pearce, C. L., \& Ensley, M. D. 2004. A reciprocal and longitudinal investigation of the innovation process: The central role of shared vision in product and process innovation teams. Journal of Organizational Behavior, 25: 259-278.

Pelled, L. H., Eisenhardt, K. M., \& Xin, K. R. 1999. Exploring the black box: An analysis of work group diversity, conflict, and performance. Administrative Science Quarterly, 44: 1-28.

Polzer, J. T., Milton, L. P., \& Swann, W. B., Jr. 2002. Capitalizing on diversity: Interpersonal congruence in small work groups. Administrative Science Quarterly, 47: 296-324.

Portes, A., \& Sensenbrenner, G. 1993. Embeddedness and immigration: Notes on the social determinants of economic action. American Journal of Sociology, 8: $1320-1350$.

Preacher, K. J., Curran, P. J., \& Bauer, D. J. 2006. Computational tools for probing interaction effects in multiple linear regression, multilevel modeling, and la- tent curve analysis. Journal of Educational and Behavioral Statistics, 31: 437-448.

Preacher, K. J., Rucker, D. D., \& Hayes, A. F. 2007. Addressing moderated mediation hypotheses: Theory, methods, and prescriptions. Multivariate Behavioral Research, 42: 185-227.

Quinones, M. A., Ford, J. K., \& Teachout, M. S. 1995. The relationship between work experience and job performance: A conceptual and meta-analytic review. Personnel Psychology, 48: 887-910.

Reagans, R., Argote, L., \& Brooks, D. 2005. Individual experience and experience working together: Predicting learning rates from knowing who knows what and knowing how to work together. Management Science, 51: 869-881.

Reagans, R., \& Zuckerman, E. 2001. Networks, diversity, and productivity: The social capital of corporate R\&D teams. Organization Science, 12: 502-517.

Rentsch, J. R., \& Hall, R. J. 1994. Members of great teams think alike: A model of effectiveness and schema similarity among team members. In J. R. Rentsch, R. J. Hall, M. M. Beyerlein, \& D. A. Johnson (Eds.), Advances in interdisciplinary studies of work teams: Theories of self-managing work teams, vol. 1: 223-261. Bingley, U.K.: Emerald.

Schmidt, F. L., Hunter, J. E., \& Outerbridge, A. N. 1986. Impact of job experience and ability on job knowledge, work sample performance, and supervisory ratings of job performance. Journal of Applied Psychology, 71: 432-439.

Sirmon, D. G., Gove, S., \& Hitt, M. A. 2008. Resource management in dyadic competitive rivalry: The effects of resource bundling and deployment. Academy of Management Journal, 51: 919-935.

Sirmon, D. G., \& Hitt, M. A. 2009. Contingencies within dynamic managerial capabilities: Interdependent effects of resource investment and deployment on firm performance. Strategic Management Journal, 30: 1375-1394.

Sirmon, D. G., Hitt, M. A., \& Ireland, R. D. 2007. Managing firm resources in dynamic environments to create value: Looking inside the black box. Academy of Management Review, 32: 273-292.

Sparrowe, R. T., Liden, R. C., Wayne, S. J., \& Kraimer, M. L. 2001. Social networks and the performance of individuals and groups. Academy of Management Journal, 44: 316-325.

Staats, B. R., Valentine, M. A., \& Edmondson, A. C. 2011. Performance tradeoffs in team knowledge sourcing. Working paper, Harvard Business School, Harvard University.

Staats, B. R. Unpacking team familiarity: The effect of geographic location and hierarchical role. Production and Operations Management, 21: 619-635. 
Starbuck, W. H. 1992. Learning by knowledge-intensive firms. Journal of Management Studies, 29: 713740.

Stasser, G., Stella, N., Hanna, C., \& Colella, A. 1984. The majority effect in jury deliberations: Number of supporters versus number of supporting arguments. Law and Psychology Review, 8: 115-127.

Stasser, G., Stewart, D. D., \& Wittenbaum, G. M. 1995. Expert roles and information exchange during discussion: The importance of knowing who knows what. Journal of Experimental Social Psychology, 31: 244-265.

Stasser; G., Taylor, L. A., \& Hanna, C. 1989. Information sampling in structured and unstructured discussions of three- and six-person groups. Journal of Personality and Social Psychology, 57: 67-78.

Stasser, G., \& Titus, W. 1985. Pooling of Unshared Information in Group Decision Making: Biased information sampling during discussion. Journal of Personality and Social Psychology, 48: 1467-1478.

Stasser, G., \& Titus, W. 1987. Effects of information load and percentage of shared information on the dissemination of unshared information during group discussion. Journal of Personality and Social Psychology, 53: 81-93.

Staw, B. M., Sandelands, L. E., \& Dutton, J. E. 1981. Threat-rigidity effects in organizational behavior: A multilevel analysis. Administrative Science Quarterly, 26: 501-525.

Steiner, I. D. 1972. Group process and productivity. New York: Academic Press.

Stewart, D. D., \& Stasser, G. 1995. Expert role assignment and information sampling during collective recall and decision making. Journal of Personality and Social Psychology, 69: 619-628.

Teece, D. J., Pisano, G., \& Shuen, A. 1997. Dynamic capabilities and strategic management. Strategic Management Journal, 18: 509-533.

Tesluk, P. E., \& Jacobs, R. R. 1998. Toward an integrated model of work experience. Personnel Psychology, 51: 321-355.

Thompson, J. 1967. Organizations in action: Social science bases of administrative theory. New York: McGraw-Hill.

Van de Ven, A. H., \& Delbecq, A. L. 1974. The effectiveness of nomininal, Delphi, and interacting group decision-making processes. Academy of Management Journal, 17: 605-621.

Van De Ven, A. H., Delbecq, A. L., \& Koenig, R., Jr. 1976. Determinants of coordination modes within organizations. American Sociological Review, 41: 322338 .
Von Hippel, E. 1988. The sources of innovation. Oxford, U.K.: Oxford University Press.

Von Nordenflycht, A. 2010 What is a professional service firm? Towards a theory and taxonomy of knowledge intensive firms. Academy of Management Review, 35: 155-174.

Wegner, D. M. 1986. Transactive memory: A contemporary analysis of the group mind. In B. Mullen \& G. R. Goethals (Eds.), Theories of group behavior: 185205. New York: Springer-Verlag.

Wegner, D. M., Erber, R., \& Raymond, P. 1991. Transactive memory in close relationships. Journal of Personality and Social Psychology, 61: 923-929.

Wernerfelt, B. 1984. A resource-based view of the firm. Strategic Management Journal, 5: 171-180.

Werr, A., \& Stjernberg, T. 2003. Exploring management consulting firms as knowledge systems. Organization Studies, 24: 881-908.

Wittenbaum, G. M., Hollingshead, A. B., \& Botero, I. C. 2004. From cooperative to motivated information sharing in groups: Moving beyond the hidden profile paradigm. Communication Monographs, 7: 59-83.

Zand, D. E. 1972. Trust and managerial problem solving. Administrative Science Quarterly, 17: 229-239.

Zarutskie, R. 2010. The role of top management tearn human capital in venture capital markets: Evidencz from first-time funds. Journal of Business Venturing, 25: 155-172.

Zollo, M., \& Winter, S. G. 2002. Deliberate learning and the evolution of Dynamic capabilities. Organization Science, 13: 339-351.

\section{APPENDIX A}

\section{Measure of the Knowledge Integration Capability ${ }^{a}$}

For each question below, please choose an answer t3 describe the communications that happened WITHIN YOUR TEAM.

Communications within our team were . .

1. Relevant-Neutral-Irrelevant

2. Timely-Neutral-Delayed

3. Objective--Neutral-Biased

4. Clear-Neutral-Confused

5. Supportive-Neutral-Inconsiderate

6. Concise-Neutral-Digressive

7. Truthful-Neutral-Deceptive

8. Non-confrontational-Neutral-Confrontational

9. Right amount-Neutral-Too many/too few

10. Fostering teamwork-Neutral-Hampering teamwork

a This measure was adapted from Leathers (1972). Items and stem are presented verbatim. 
$\Delta$

Heidi K. Gardner (hgardner@hbs.edu) is an assistant professor of business administration at Harvard Business School, Harvard University. She received her Ph.D. in organizational behavior from the London Business School. Her research focuses on team effectiveness, leadership, collaboration, and innovation in knowledge-intensive environments, particularly professional service firms.

Francesca Gino (fgino@hbs.edu) is an associate professor of business administration at Harvard Business School, Harvard University. She received her Ph.D. in economics and management from the Sant'Anna School of Ad- vanced Studies. Her research focuses on judgment and decision making, social influence, group dynamics, and ethics.

Bradley R. Staats (bstaats@unc.edu) is an assistant professor in the operations, technology and innovation management area at the Kenan-Flagler Business School at the University of North Carolina at Chapel Hill. He received his doctorate in technology and operations management from Harvard Business School. His research focuses on how the ongoing fragmentation of work affects individual and team learning and productivity. 
Copyright of Academy of Management Journal is the property of Academy of Management and its content may not be copied or emailed to multiple sites or posted to a listserv without the copyright holder's express written permission. However, users may print, download, or email articles for individual use. 